\title{
A Review of Factors Affecting the Burning Behaviour of Wood for Application to Tall Timber Construction
}

\author{
Alastair I. Bartlett*, Rory M. Hadden and Luke A. Bisby \\ School of Engineering, The University of Edinburgh, The King's Buildings, \\ Mayfield Road, Edinburgh EH9 3DW, UK
}

Received: 27 February 2018/Accepted: 30 October 2018

\begin{abstract}
This paper presents a review of the pyrolysis, ignition, and combustion processes associated with wood, for application in tall timber construction. The burning behaviour of wood is complex. However the processes behind pyrolysis, ignition, combustion, and extinction are generally well understood, with good agreement in the fire science literature over a wide range of experimental conditions for key parameters such as critical heat flux for ignition $\left(12 \mathrm{~kW} / \mathrm{m}^{2} \pm 2 \mathrm{~kW} / \mathrm{m}^{2}\right)$ and heat of combustion $(17.5 \mathrm{MJ} / \mathrm{kg} \pm 2.5 \mathrm{MJ} / \mathrm{kg})$. These parameters are key for evaluating the risks posed by using timber as a construction material. Conversely, extinction conditions are less well defined and understood, with critical mass loss rates for extinction varying from $2.5 \mathrm{~g} / \mathrm{m}^{2} \mathrm{~s}$ to $5 \mathrm{~g} / \mathrm{m}^{2} \mathrm{~s}$. A detailed meta-analysis of the fire resistance literature has shown that the rate of burning as characterised by charring rate averaged over the full test duration is observed to vary with material properties, in particular density and moisture content which induce a maximum $18 \%$ variability over the ranges expected in design. System properties are also shown to be important, with stochastic phenomena such as delamination and encapsulation failure resulting in changes to the charring rate that cannot be easily predicted. Finally, the fire exposure as defined by incident heat flux has by far the largest effect on charring rates over typical heat fluxes experienced in compartment fires. Current fire design guidance for engineered timber products is largely prescriptive, relying on fixed "charring rates" and "zero-strength layers" for structural analyses, and typically prescribing gypsum encapsulation to prevent or delay the involvement of timber in a fire. However, it is clear that the large body of scientific knowledge that exists can be used to explicitly address the fire safety issues that the use of timber introduces. However the application of this science in real buildings is identified as a key knowledge gap which if explored, will enable improved efficiencies and innovations in design.
\end{abstract}

Keywords: Timber, Fire, Pyrolysis, Charring, Fire safety engineering, Building design

* Correspondence should be addressed to: Alastair I. Bartlett, E-mail: alastair.bartlett@ed.ac.uk 


\section{Introduction}

Engineered timber products such as cross-laminated timber (CLT) and glued-laminated timber (GLT) are increasingly popular in the construction industry due to their attractive environmental and aesthetic credentials, as well as their applicability for prefabrication and rapid on-site construction and potential for use in multi-storey timber buildings. One factor discouraging its widespread uptake in highrise buildings is uncertainty as to its performance in the event of fire. The majority of existing research on structural fire performance of timber elements focuses on determining effective charring rates, with limited scientific understanding of its behaviour in real (as opposed to standard) fire scenarios. As a result, current structural design guidance focuses on prescribing a fixed (nominal) charring rate, with an additional fixed "zero-strength" layer assumed to account for reductions in mechanical properties of the heated timber behind the char line [1]. In reality, the structural performance of timber in fire depends on numerous parameters, including density, moisture content, species, sample geometry, and heating conditions. Various researchers have investigated the effects of these parameters; the current paper reviews the available literature focusing on applications of modern mass timber construction.

In terms of accounting for the flammability of exposed timber, this is sometimes limited or prohibited by building codes, with arbitrary height limits set on timber construction in many jurisdictions [2]. As such, many CLT buildings to date have been fully encapsulated within gypsum plasterboard protection to satisfy such requirements, preventing full realisation of architects' aspirations to visually express structural mass timber. To allow fire safe use of exposed structural timber elements, the processes driving the pyrolysis, ignition, and subsequent combustion of timber must be understood. These processes are also discussed herein, and the relevant literature reviewed.

\section{Burning Behaviour}

\subsection{Pyrolysis}

Pyrolysis is the process by which materials decompose upon exposure to heat. This process effects chemical and physical changes, and thus understanding and quantifying the processes is fundamental to the ignition, burning, and extinction behaviour of a material. To burn, polymers must first decompose into smaller molecules that can exist in the gas phase at ambient conditions. To create a selfsustaining reaction, the combustion of these gases must generate sufficient heat to perpetuate the production of volatiles [3]. Upon heating, the constituent natural polymers present in timber will degrade, producing inert and combustible gases (the nature and composition of which will depend on the char yield [4]), liquid tars, a solid carbonaceous char (typically around $20 \%$ the density of virgin wood [5]) and inorganic ash. This can occur before dehydration is completed if the heating rate is fast enough, but will be faster after the sample has dried [6]. Under sustained heating conditions, these pyrolysis products can then undergo further 
pyrolysis themselves [7]. This process is further complicated due to charring and material variability [7], and the chemical processes occurring are numerous and interdependent [8]. It is also necessary to distinguish between pyrolysis and combustion. Pyrolysis refers to the thermal decomposition of a substance, is endothermic, and can occur without an oxidiser.

In most scenarios relevant to timber construction it can be assumed that pyrolysis occurs over a relatively narrow zone perpendicular to the exposed face of the material. Wood typically undergoes three main stages of pyrolysis [9] due to its relatively low thermal conductivity and density and relatively high specific heat: dehydration and very slow pyrolysis below $200^{\circ} \mathrm{C}$, onset of pyrolysis up to $300^{\circ} \mathrm{C}$, and rapid pyrolysis above $300^{\circ} \mathrm{C}$.

Detailed pyrolysis reviews are available elsewhere $[10,11]$, however some of the key aspects relevant to timber construction, in particular moisture transport, charring, and production of flammable gases are discussed below.

2.1.1. Moisture Transport Upon heating, and prior to the onset of pyrolysis, free water begins to evaporate as temperatures within a timber member approach $100^{\circ} \mathrm{C}$. Some water vapour will migrate deeper into the sample (away from the source of heat) [6, 7, 12-14], and re-condense [15] This increases the local moisture content [7, 13, 14]. This then creates three zones - a dry zone closest to the exposed face (in which pyrolysis occurs); a dehydrating zone; and a wet zone [14], as illustrated in Fig. 1. It is assumed that most [6] of the water vapour, however,

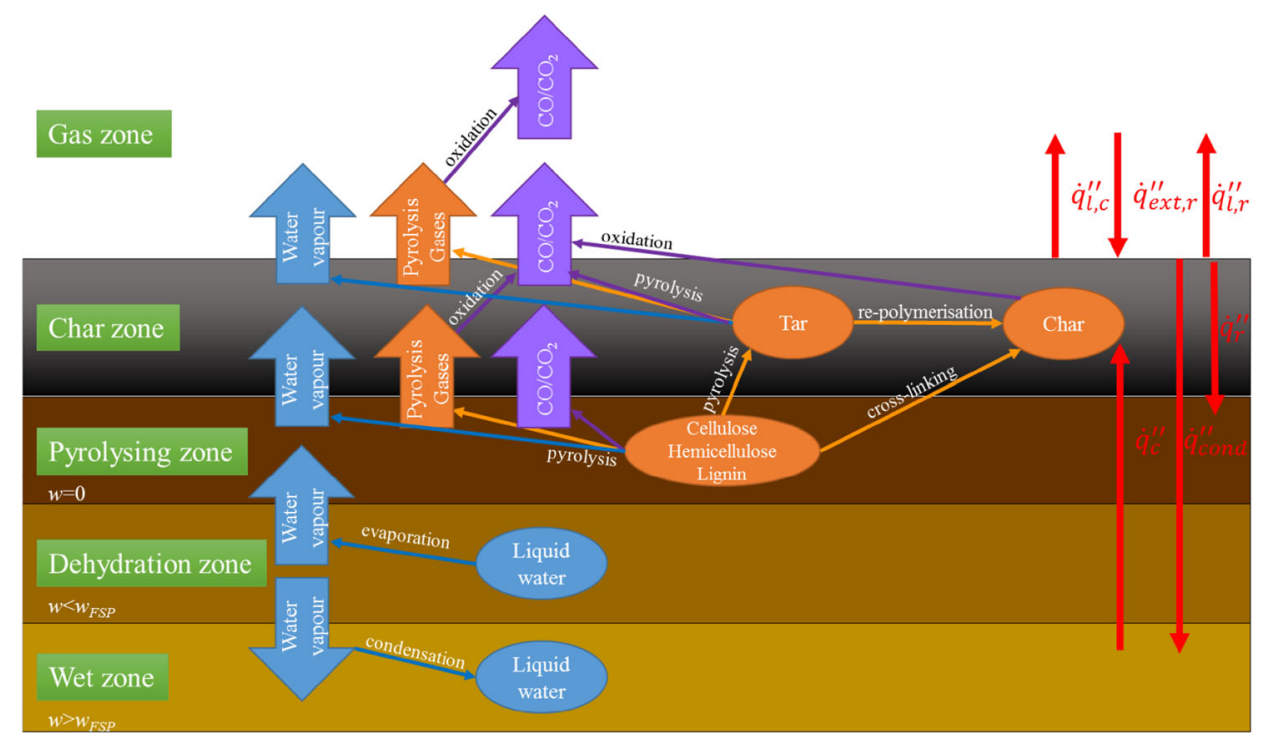

Figure 1. Chemical and physical processes within a burning timber sample; $\dot{q}_{l, c}^{\prime \prime}$ is the surface heat losses by convection, $\dot{q}_{l, r}^{\prime \prime}$ is the surface heat losses by radiation, $\dot{q}_{e x t, r}^{\prime \prime}$ is the external heat flux, $\dot{q}_{r}^{\prime \prime}$ is in-depth radiation, $\dot{q}_{c o n d}^{\prime \prime}$ is conduction into the sample, and $\dot{q}_{c}^{\prime \prime}$ is convective heat transfer through cracks in the sample. 
leaves from the surface $[6,7,12,13]$. At low heat fluxes, dehydration and pyrolysis will take place independently; at higher heat fluxes they will occur simultaneously $[5,16]$. Where dehydration and pyrolysis occur simultaneously, moisture slows the temperature rise [16, 17], typically until reaching $115^{\circ} \mathrm{C}[18]$, due to the energy supplied being used for evaporation rather than heating, and cools the pyrolysis zone through convective mass flow of water vapour [16]. Bound water is typically freed later, at temperatures around $240^{\circ} \mathrm{C}$ [19].

2.1.2. Low Temperature Charring Phenomena Whilst pyrolysis is typically simplified into "charring" for structural applications (which is assumed to occur at $300^{\circ} \mathrm{C}$ ), there are additional steps in the pyrolysis process which can affect a timber member's load-bearing capacity. Mass loss due to pyrolysis occurs slowly at temperatures below $200^{\circ} \mathrm{C}[5,9,17]$, with pyrolyzate consisting mostly of noncombustible volatiles such as carbon dioxide, formic acids, and acetic acids $[5,7$, 20, 21]. However prolonged heating at low temperatures can convert hemicellulose (and lignin) into a carbonaceous char [20] at temperatures as low as $95^{\circ} \mathrm{C}[9]$ or $120^{\circ} \mathrm{C}$ [4], leaving cellulose largely unreacted [22]. Cellulosic materials have no fluid state, but can soften before breaking down into vapours [3]. In so doing, they may undergo a glass transition, altering their structure and becoming softer and more rubbery [3]. For lignin, this occurs at temperatures around $55^{\circ} \mathrm{C}$ to $170^{\circ} \mathrm{C}[19,23-26]$; permanent reductions in strength of timber have been observed at temperatures as low as $65^{\circ} \mathrm{C}$ [20]. When the temperature exceeds $200^{\circ} \mathrm{C}$, the pyrolysate remains mainly non-combustible, however visible discolouration will begin $[4,13]$ or become more intense [18], with prolonged exposure to these temperatures causing slow charring $[8,9]$. Uncharred wood remains at moderate temperatures even in long fires due to the high heat losses from the char layer [3, 13, 27]; at a depth of $6 \mathrm{~mm}$ below the charline, the temperature is typically reduced to around $180^{\circ} \mathrm{C}$ [20]; with a total thickness of approximately $35 \mathrm{~mm}$ below the char layer being heated $[5,13,28]$. The resulting temperature profile below the char line can be expressed as an exponential or power term for thermally thick wood [20], or alternatively as a quadratic function [13]. The main pyrolysis reactions then typically begin from $225^{\circ} \mathrm{C}$ to $275^{\circ} \mathrm{C}$ [7].

2.1.3. High Temperature Charring Phenomena Hemicellulose is typically the first component of wood to undergo thermal decomposition. The temperatures at which this reaction starts are reported over a wide range from $120^{\circ} \mathrm{C}$ to $180^{\circ} \mathrm{C}$ [19], $200^{\circ} \mathrm{C}$ to $260^{\circ} \mathrm{C}[3,4,9], 220^{\circ} \mathrm{C}$ to $315^{\circ} \mathrm{C}[29,30]$, or $200^{\circ} \mathrm{C}$ to $300^{\circ} \mathrm{C}$ [20]. This temperature range is dependent on the heating rate, species, density, or moisture content [5].

Cellulose is typically the next compound to decompose, with decomposition temperatures (which likely have the same dependencies as those for hemicellulose) quoted as $240^{\circ} \mathrm{C}$ to $350^{\circ} \mathrm{C}$ [4, 9], $250^{\circ} \mathrm{C}$ to $350^{\circ} \mathrm{C}$ [3], $315^{\circ} \mathrm{C}$ to $400^{\circ} \mathrm{C}$ [29], $280^{\circ} \mathrm{C}$ to $400^{\circ} \mathrm{C}$ [19] or $300^{\circ} \mathrm{C}$ to $350^{\circ} \mathrm{C}$ [20]. Cellulose may decompose via two main processes: the first by breaking a link in the carbon ring, cross-linking to produce char alongside carbon monoxide, carbon dioxide, and $\mathrm{H}_{2} \mathrm{O}[3,4,31]$; the second is chain scission [3] when a link in the polymer chain is broken and levoglucosan 
molecules can break away [4], typically at temperatures around $250^{\circ} \mathrm{C}$ to $300^{\circ} \mathrm{C}$ [3]. Levoglucosan is a tar which will break down further into combustible gases [3, 31-33], or alternatively repolymerise to form char [20, 32, 33]. Low heating rates tend to favour char formation [4, 16, 31,34] alongside largely non-combustible vapours, thus releasing energy [9]. High heating rates favour the production of levoglucosan [34], yielding flammable vapours and little or no char [16, 20], thus consuming energy [9].

Lignin usually undergoes pyrolysis at temperatures quoted as $110^{\circ} \mathrm{C}$ to $400^{\circ} \mathrm{C}$ [19], $280^{\circ} \mathrm{C}$ to $500^{\circ} \mathrm{C}[3,4,9]$ or $225^{\circ} \mathrm{C}$ to $450^{\circ} \mathrm{C}$ [20]. Schaffer [19] found that lignin began melting around $160^{\circ} \mathrm{C}$, followed by re-hardening from $160^{\circ} \mathrm{C}$ to $210^{\circ} \mathrm{C}$, with only $10 \%$ of its weight loss having occurred by $280^{\circ} \mathrm{C}$. Lignin produces aromatic products on pyrolysis [9], and yields more char than cellulose [4, 5, 9] - upon heating to $400^{\circ} \mathrm{C}$ to $450^{\circ} \mathrm{C}$, approximately half of lignin remains as char [4], contributing significantly to the char yield [3]. Since softwoods have higher lignin contents than hardwoods, they consequently give higher char yields [4]; this has implications for the burning rates of softwoods compared to hardwoods.

At temperatures between $300^{\circ} \mathrm{C}$ and $500^{\circ} \mathrm{C}$, pyrolysis rates increase rapidly [7, $9,20,21,35]$ and are accompanied by additional exothermic reactions [9] which cause the temperatures to increase rapidly unless evolved heat can be dissipated [9]. The pyrolyzate now contains flammable gases [17, 21], and as such flaming ignition will usually have occurred by the time the surface reaches these temperatures. These gases also carry drops of highly flammable tars appearing as smoke $[9,33]$; this favours the production of levoglucosan [34]. This rapid decomposition results in a residual char $[5,7,9]$, which is less easily volatilised than the virgin wood [3, 32].

Overall, there is strong agreement that temperatures around $300^{\circ} \mathrm{C}$ represent the onset of rapid pyrolysis and char formation although under certain conditions, e.g. extended heating durations, this can occur at significantly lower temperatures. There is reasonable agreement between authors on the order in which constituent polymers react, their chemical processes, and their char yields, but there is wide scatter in the literature regarding important properties such as decomposition temperatures. These differences may be partially attributed to differences in species, heating rate, and testing methods. It is unlikely that an engineering design will account for these factors however, it is necessary that the designers are aware of the chemical processes that will ultimately determine the thermal and mechanical properties of timber when exposed to fire. These data are however essential in developing detailed models of timber pyrolysis that will form the basis of simplified design calculations. It is likely that in engineering design other parameters will bring additional uncertainty and the relative uncertainties must be assessed to ensure robust designs.

2.1.4. Heat Transfer Limitations The rigid char left behind by pyrolysis will play a significant role in the heat transfer to the virgin timber.

The physical properties of the char most importantly density, thermal conductivity, heat capacity, continuity, coherence, adherence, susceptibility to oxidation, and permeability, will affect the continued thermal decomposition of the virgin 
material [3]. Once a porous char has formed, there are significant differences to the heat transfer mechanisms that leads to further heating of virgin wood. Cracks formed in the char result in different heat transfer mechanisms to those in virgin wood [5, 11, 13]. For example instead of conduction dominating, radiative heat transfer though the char pores will dominate [32] This can compromise one-dimensional heat transfer assumptions commonly made in analyses [36]. Cracks allow the ready escape of volatiles towards the surface $[4,11,13]$. Once the char layer has formed there is a gradual decline in mass flux [6, 35]. Additionally, char has a greater emissivity and absorptivity than that of wood (around 0.95 compared to 0.7) [32]. The char yield from cellulose is heavily dependent on organic impurities, with pure $\alpha$-cellulose (washed thoroughly to remove impurities) yielding only $5 \%$ char upon prolonged heating at $300^{\circ} \mathrm{C}$, but viscose rayon (having a relatively high concentration of impurities) giving up to $40 \%$ [4].

\subsection{Ignition}

Once pyrolysis is underway, in the presence of oxygen, the products of pyrolysis may then undergo a rapid, exothermic combustion reaction. This is discussed in detail in Sect. 2.3, however, the process of the onset of combustion, i.e. ignition, demands its own discussion. Ignition can lead to either smouldering or flaming combustion, however flaming combustion is the focus herein unless otherwise noted. Furthermore, ignition can either be piloted, in which a spark or flame energises the gaseous species, or unpiloted, where the volatiles must achieve the necessary energy for ignition through heating alone.

Criteria for ignition are typically defined by either the "critical heat flux", the lowest heat flux for which ignition will occur, or the "critical surface temperature", the lowest surface temperature for which ignition will occur. Values for these criteria for timber from various studies are presented in Table 1. It can be seen that there is reasonable agreement across studies, and that critical heat fluxes for piloted and unpiloted ignition are around 10 to $13 \mathrm{~kW} / \mathrm{m}^{2}$ and 25 to $33 \mathrm{~kW} / \mathrm{m}^{2}$ respectively, with the results of Hottel [37] and Simms [38] appearing to be outliers, potentially due to their use of significantly different apparatus. There is much more scatter in the results for critical surface temperature, but in each case, ignition occurs at temperatures well below those experienced in fires (typically 900- $1100^{\circ} \mathrm{C}$ [4]). Critical surface temperature for ignition is also heavily dependent on the external heat flux, due in part to differences in the time taken to build up a char layer and how much energy it absorbs [39].

In reality, ignition properties will vary with test setup [4, 20, 39-43], sample orientation [4, 40], ambient temperature [36], and heat transfer mode [4, 20, 36, 43, 44]; auto-ignition temperature can vary by more than $150^{\circ} \mathrm{C}$ for the same material depending on external factors, however introduction of a pilot can reduce the effects of environmental variables [36]. In addition, density, moisture content, thickness, arrangement of wood pieces, and time are all important for the amount of heat necessary for ignition [45], with wood pieces above $10 \mathrm{~mm}$ thick not being easily ignitable [46]. Spontaneous ignition can be aided by exothermic char oxidation, which causes an increase in surface temperature, which can then raise the gas 


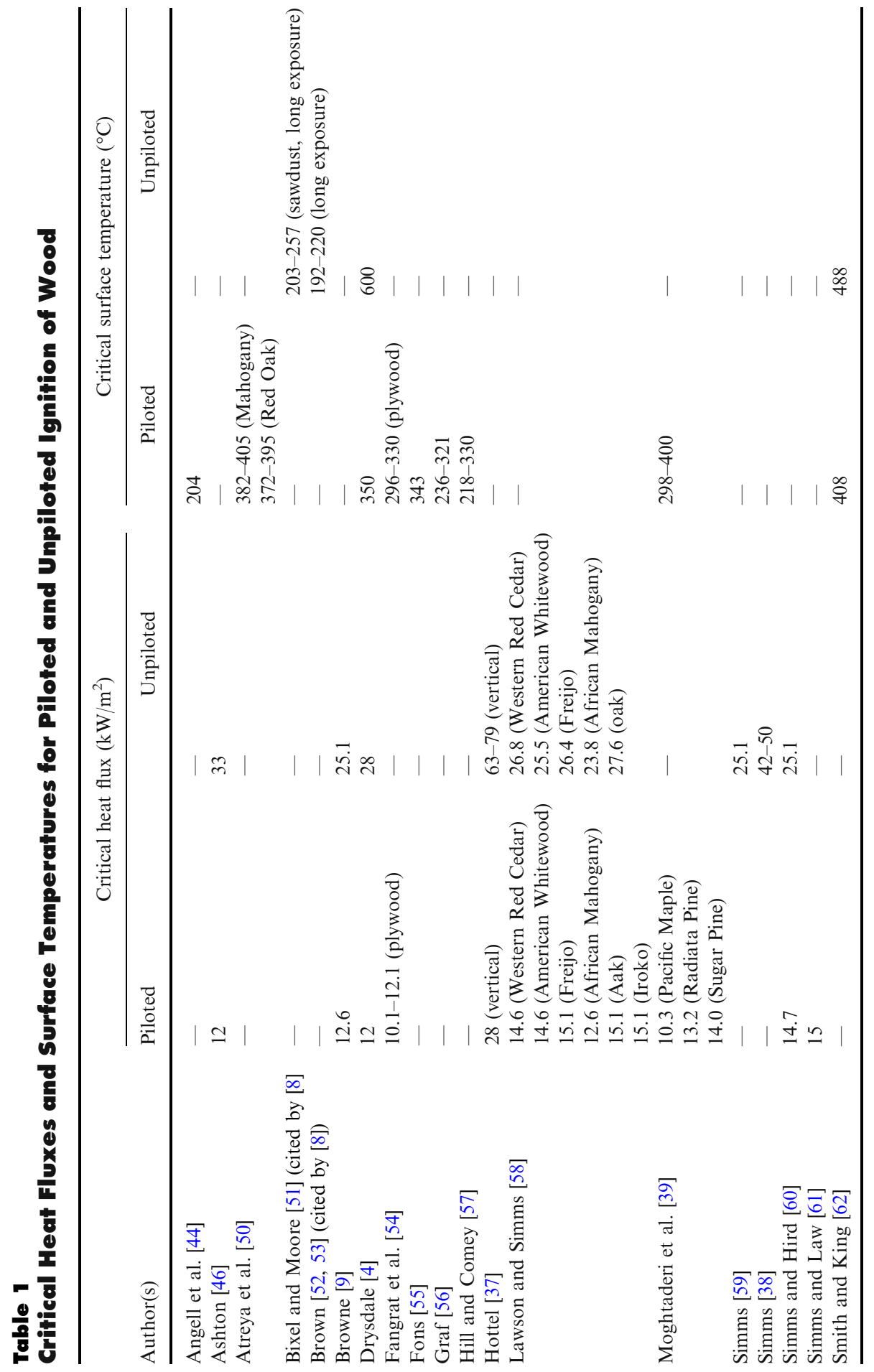




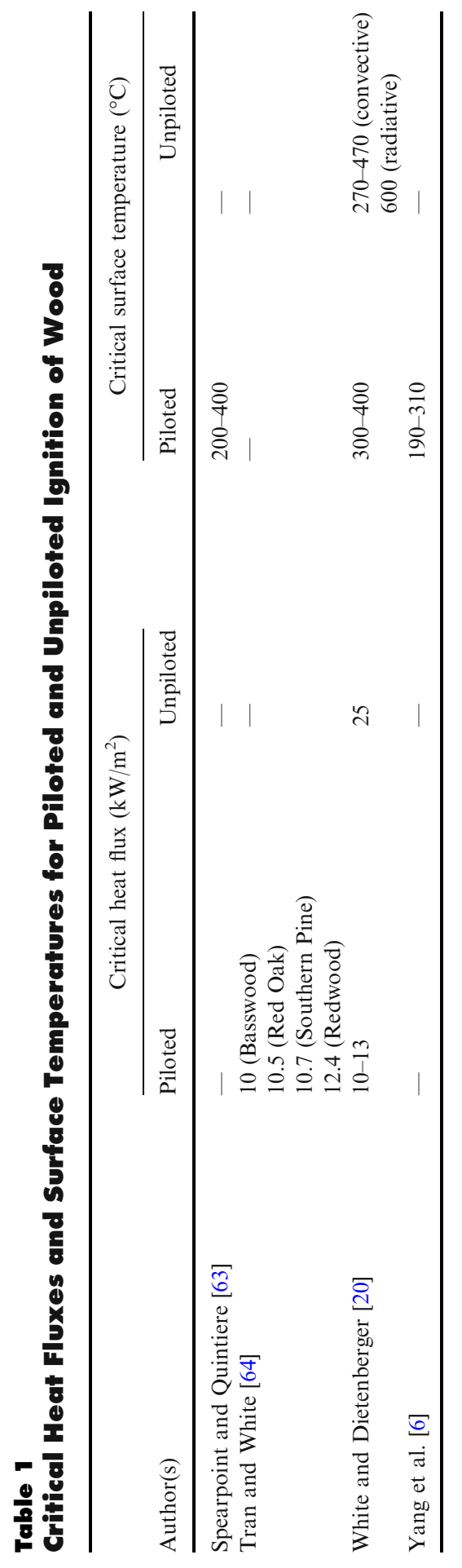


temperature to that required for ignition [32]. Sustained smouldering ignition has been found to occur around heat fluxes of 5 to $10 \mathrm{~kW} / \mathrm{m}^{2}[33,47]$ typically at surface temperatures around $200^{\circ} \mathrm{C}[20]$.

Rather than the incident heat flux or surface temperature being the key factor that affects ignition, the gas phase temperature is most important [4, 20, 32]. For ignition to occur, a flammable mixture must exist somewhere in the gas phase, which must then be elevated to a temperature at which a combustion reaction can occur $[20,36,48]$. This can be split into two segments - the pyrolysis time (the time needed to produce a flammable mixture), and the induction time (the time needed for the temperature to reach one at which ignition can occur) [36]. Typically the pyrolysis time dominates [36]. Prior to ignition, the gradually increasing surface temperature may be subject to a number of temperature "spikes" corresponding to flashes before sustained ignition is achieved [49]. Drysdale [4] suggests that to generate the necessary conditions for ignition, a critical mass flow rate of volatiles from the surface must be achieved, given by Eq. (1):

$$
\left(\phi \Delta H_{c}-L_{v}\right) \dot{m}_{c r}^{\prime \prime}+\dot{q}_{e}^{\prime \prime}-\dot{q}_{l}^{\prime \prime}>0
$$

where $\phi$ is the fraction of the heat of combustion of the vapour transferred back to the surface, typically around $0.3, \Delta H_{c}$ is the heat of combustion, $L_{v}$ is the heat of gasification, $\dot{m}_{c r}^{\prime \prime}$ is the critical mass flow rate of volatiles, $\dot{q}_{e}^{\prime \prime}$ is the external heat flux, and $\dot{q}_{l}^{\prime \prime}$ is the heat losses.

Formulae for time to ignition exist to attempt to simplify the gas phase problem, which is complex both to predict and model [65], and varies according to the parameters discussed above, particularly at lower heat fluxes [40]. Various relationships exist for thermally thin solids [Eq. (2)] and thermally thick solids [Eq. (3)]:

$$
\begin{aligned}
& t_{i g}=\rho C_{p} l \frac{T_{s, i g}-T_{\infty}}{\dot{q}_{n}^{\prime \prime}} \\
& t_{i g}=\frac{\pi}{4} k \rho C_{p}\left(\frac{T_{s, i g}-T_{\infty}}{\dot{q}_{n}^{\prime \prime}}\right)^{2}
\end{aligned}
$$

where $T_{s, i g}$ is the surface temperature at ignition, $T_{\infty}$ is the ambient temperature, $\dot{q}_{n}^{\prime \prime}$ is the net heat flux to the surface, and $l$ is the sample thickness. Whilst lower heat fluxes will yield longer ignition times (e.g. White and Dietenberger [20] found times to ignition of $3 \mathrm{~s}$ at $55 \mathrm{~kW} / \mathrm{m}^{2}$ and $930 \mathrm{~s}$ at $18 \mathrm{~kW} / \mathrm{m}^{2}$ ), the internal temperatures at the point of ignition will be higher [6]. Pyrolysis time decreases with flow velocity (as there is better heat transfer to the surface), whereas the induction time increases (as the residence time in the gas phase is less) [36]. Thus a middling flow velocity will produce the most rapid auto-ignition.

Moisture delays ignition, and increases the minimum intensity required for ignition [16]; for wood it has been found that $t_{i g} \propto(1+4 w)^{2}$ where $w$ is the moisture 
content (dimensionless) [65]. Dry wood will thus ignite in about half the time of wood with typical $12 \%$ moisture content (under these conditions).

Simms [59] explored the effect of sample absorptivity at the surface by testing the ignition properties of oak and mahogany both at their natural colours, and coated with carbon black. He found that the minimum critical heat fluxes to ignite oak and mahogany respectively were around 35 to $45 \%$ lower and 10 to $30 \%$ lower when coated with carbon black. This difference is time-variant, as samples will naturally blacken and char with increased heat exposure.

Several differences are noted between piloted and unpiloted (or auto-) ignition. Drysdale [4] notes that auto-ignition occurs at a lower surface temperature with convective heating than with radiative heating, whereas piloted ignition occurs at a lower surface temperature with radiative heating than with convective heating - a forced convective flow will dilute flammable gases, thus requiring more heating to reach a flammable mixture, however, this will increase the temperature of the gas/air mixture, raising it above its auto-ignition temperature sooner than under radiant heating. He further notes that auto-ignition occurs more readily on horizontal surfaces than on vertical surfaces, as vertical surfaces are exposed to more effective convective cooling than horizontal ones and volatiles will be more diluted. Whilst this may be the case for test setups, the complex fire dynamics of a compartment may mean that the trend is somewhat different in reality. If there is no pilot flame, ignition may (depending again on experimental conditions) not occur until pyrolysis below the char layer slows sufficiently to allow the char to come into contact with the air [9]. Charcoal has the lowest spontaneous ignition temperature of all the combustion products, reported as low as 150 to $250^{\circ} \mathrm{C}$ [9].

The nature of the pilot source will also affect the ignition criteria, both its power and location, with power having the greatest influence [66]. Ignition with an impinging flame can occur at much lower heat fluxes than regular piloted ignition $\left(4 \mathrm{~kW} / \mathrm{m}^{2}\right.$ compared with $12 \mathrm{~kW} / \mathrm{m}^{2}$ for pinewood) [4]. The size and properties of the impinging flame govern; as size of the flame increases, the dominant mode of heat transfer will move from convection to radiation [4], and the flame will provide an additional heat flux, which is difficult to quantify. This has serious implications for scaling from tests with sparks as ignition sources to walls with burning furniture adjacent acting as the ignition source. Drysdale [4] found that for vertical wood samples with a pilot flame, the piloted ignition temperature was around $320^{\circ} \mathrm{C}$ to $325^{\circ} \mathrm{C}$, increasing as the flame moved away from the surface, with the time to ignition also increasing.

Piloted ignition will only occur when the pilot is within the visible stream of volatiles [38]. Simms [38] and Simms and Hird [60] found this distance to be around $20 \mathrm{~mm}$ for vertical samples with a surface area of $50 \times 50 \mathrm{~mm}$, with ignition times increasing as distance between the sample and the pilot flame increases. Simms [38] distinguishes two types of piloted ignition: regular piloted ignition, in which the flame is not in contact with the surface; and surface ignition, in which the flame spreads over the igniting surface. Ignition occurs much earlier and at lower heat fluxes $\left(4.2 \mathrm{~kW} / \mathrm{m}^{2}\right.$ compared with $\left.14.6 \mathrm{~kW} / \mathrm{m}^{2}\right)$ for surface radiation than for piloted ignition [38], as would be the case during flame spread across a surface. 
Due to the insulating qualities of char, if ignition has not occurred by the time a char layer has formed then the presence of char will require a higher surface temperature to provide the necessary heat flux to the virgin wood [4].

McAllister et al. [41, 42] note that whilst ignition theories based on temperature or heat flux are only applicable in the conditions in which they were measured, a critical mass flux as suggested by Drysdale [4] [Eq. (1)] can be applied across various apparatus and length scales. If a fuel and air mixture exists within flammability limits, a premixed flame will form in the presence of a pilot source. For this to self-sustain, generation of pyrolysis gases must be sufficient that the heat losses from the flame are not enough to extinguish it. Temperature and the rate of heat release from the flame increase with the fuel to air ratio, thus there is a critical mass flux required to initiate and sustain flaming. This has been found to increase with heat flux, possibly due to a steeper temperature gradient, with only a small surface region at a sufficient temperature to pyrolyse.

\subsection{Flaming Combustion}

After the ignition of these pyrolysis gases, the pyrolysis products will undergo combustion, a process involving the mixing of pyrolysis gases with ambient air. The heat generated thereby can then further drive the pyrolysis processes discussed in Sect. 2.1 [67]. Oxidation in the gas phase of volatiles produced by thermal degradation produces flaming combustion, and solid-phase char oxidation produces smouldering combustion [5]. The heat of combustion of wood is about $15-20 \mathrm{MJ} / \mathrm{kg}[7,68]$, about half to two-thirds of which is released through flaming, the rest through smouldering $[9,17,63]$. Cellulose is the main contributor to flaming combustion [69], as it has been demonstrated (Sect. 2.1) to produce more volatiles than char.

After ignition, the majority of the available oxygen will be consumed by the flame, thus post-ignition thermal decomposition will occur in a largely vitiated environment [3]. During stable flaming, volatiles produced by the decomposing wood are transported just outside the solid material into the reaction zone [7], with flaming combustion occurring entirely in the gas phase [9], thus the rate of combustion is mainly determined by the rate of pyrolysis [7].

The flow of volatiles is defined by the flames and the environment geometry, and produce complex flow patterns; these patterns will differ somewhat from the more simplistic scenarios in standard test methods [36]. The fire size influences the mass flux from fuels due to heat feedback from gas-phase combustion [70]. Since char has a much lower thermal conductivity than wood, it delays the onset of pyrolysis of the virgin wood [9]. Thus, flaming is often strong at first, before weakening until the deeper wood portions can be pyrolysed $[9,12,20,63]$. The flame provides an additional heat flux to that provided by the external source [71]. The heat from the flame, however, is not enough to provide sustained burning on its own [71]. The heat flux from the flame is intimately coupled to the burning rate which can be considered constant after the initial strong flaming [63]. Just after ignition, the net heat flux can be given by Eq. (4) from [63]. 


$$
\dot{q}_{\mathrm{n}}^{\prime \prime}=\dot{q}_{\mathrm{e}}^{\prime \prime}+\dot{q}_{\mathrm{f}}^{\prime \prime}-\sigma\left(T_{s}^{4}-T_{\infty}^{4}\right)
$$

where $\dot{q}^{\prime \prime}$ is the heat flux, with subscripts $\mathrm{n}$, e, and f representing net heat flux, external heat flux, and heat flux from the flames respectively; $\sigma$ is the StefanBoltzmann constant; $T_{S}$ is the surface temperature, and $T_{\infty}$ the ambient temperature. This equation is considerably simplified, as it does not consider heat losses by conduction through the solid, heat losses by convection, or cross-radiation between burning surfaces, all of which must be considered in a real fire. A more complete equation would be:

$$
\dot{q}_{\mathrm{n}}^{\prime \prime}=\dot{q}_{\mathrm{e}}^{\prime \prime}+\dot{q}_{\mathrm{f}}^{\prime \prime}-\sigma\left(T_{s}^{4}-T_{\infty}^{4}\right)-h_{c}\left(T_{s}-T_{\infty}\right)-k \frac{\partial T}{\partial x}
$$

where $h_{c}$ is the convective heat transfer coefficient.

\subsection{Flame Extinction}

The concept of flaming extinction is an important consideration when using engineered timber products within a compartment. Since any exposed timber will add to the fuel load and burn as described above, it is vital to understand the conditions in which it will continue to burn, and the conditions in which it will extinguish.

Piloted ignition and flame extinction at a sample surface have the same critical conditions - assuming chemical composition of volatiles is the same at both conditions $[4,72]$. Both can be related to fire point conditions [7]. A flame will extinguish if its heat losses exceed its heat release [73]. For this to occur, the mass flux of flammable gases must drop below a critical value [4]. Extinction is possible above the critical mass flux, but such samples are then susceptible to re-ignition [4]. Extinction is governed by the oxidation kinetics, and is difficult to accurately predict [73].

One critical extinction parameter is the Damköhler number [73] - the ratio of heat loss time (defined as $k T / \delta^{2}$, where $\delta$ is the thermal boundary layer, and can be expressed as $\alpha / u_{\infty}$ ) to reaction time (simply defined as the mass loss rate multiplied by the heat of combustion), which can be found from Eq. (6):

$$
D a=\frac{\dot{m}^{\prime \prime \prime} \Delta H_{c}}{k T u_{\infty}^{2} / \alpha^{2}}
$$

where $\dot{m}^{\prime \prime \prime}$ is the mass loss rate per unit volume, $u_{\infty}$ is the ambient gas velocity, and $\alpha$ is the thermal diffusivity. When applying Eq. (6) to timber, it is important to note that the thermal conductivity and diffusivity are temperature-dependent. Quintiere and Rangwala [73] propose Eq. (7) for determining the critical mass flux for extinction, based on Tewarson and Pion's [74] work on PMMA. This expression highlights a clear dependence on oxygen concentration, external heat flux, and heat losses. 


$$
\dot{m}_{c r, e x}^{\prime \prime}=\frac{1}{L_{v}}\left[\frac{h_{c}}{C_{p}}\left[\frac{Y_{o x, \infty} \Delta H_{c}}{v}-C_{p}\left(T_{p}-T_{\infty}\right)\right]+\dot{q}_{e, r}^{\prime \prime}-\sigma\left(T_{p}^{4}-T_{\infty}^{4}\right)\right]
$$

where $L_{v}$ is the heat of vaporisation, $Y_{o x, \infty}$ is the ambient oxygen concentration, $v$ is the stoichiometric oxygen-fuel ratio, $T_{p}$ is the pyrolysis temperature, and $\dot{q}_{e, r}^{\prime \prime}$ is the external radiant heat flux.

The mass loss rate per unit area can be expressed in terms of the imposed heat flux by Eq. (8):

$$
\dot{m}^{\prime \prime}=\frac{\dot{q}_{e}^{\prime \prime}+\dot{q}_{f}^{\prime \prime}-\dot{q}_{l}^{\prime \prime}}{L_{v}}
$$

where $L_{v}$ is the heat of gasification (typically $1820 \mathrm{~kJ} / \mathrm{kg}$ for wood [74]), equal to $\Delta H_{v}+C_{p}\left(T_{p}-T_{\infty}\right)$, where $\Delta H_{v}$ is the heat of vaporisation. It should be noted that at extinction, the heat losses must consider the effect of the char layer. Since gasification will occur for the virgin wood rather than the char, it is the net heat flux at the char-timber interface that is of interest. At this point, the timber has already been raised to the pyrolysis temperature, thus $L_{v}=\Delta H_{v}$.

Bamford et al. [18, 75] noted that for $230 \mathrm{~mm} \times 230 \mathrm{~mm}$ wood panels of varying thicknesses from $9.5 \mathrm{~mm}$ to $50.8 \mathrm{~mm}$ and heated by flames on two sides, after a given period of time, flaming was self-sustaining upon removal of external heat sources. Panels heated only on one side, however, did not achieve self-sustained flaming if over $3 \mathrm{~mm}$ thick. The time to reach sustained flaming was proportional to the square of sample thickness, with thicker samples taking longer. They found that the centreline temperature at the time of self-sustained burning was always around $200^{\circ} \mathrm{C}$. They relate the conditions necessary for self-sustained flaming to the rate of volatile production, finding that a rate of $2.5 \mathrm{~g} / \mathrm{m}^{2} \mathrm{~s}$ was required for self-sustained burning.

Subsequently experiments were undertaken on $50 \mathrm{~mm}$ thick oak and Columbian pine samples at heat fluxes ranging from $18 \mathrm{~kW} / \mathrm{m}^{2}$ to $54 \mathrm{~kW} / \mathrm{m}^{2}$. Samples subjected to heat fluxes at or below $30 \mathrm{~kW} / \mathrm{m}^{2}$ extinguished after around 2 to $7 \mathrm{~min}$, reaching char depths of around 4 to $8 \mathrm{~mm}$. The samples subjected to $50 \mathrm{~kW} / \mathrm{m}^{2}$ however, continued burning until the majority of the sample had charred.

Further experiments [18] explored the combustion behaviour of two vertical wood panels set parallel and opposite to each other. The thickness of the samples was found to have no obvious effect. Square panels of length $229 \mathrm{~mm}$ and rectangular panels $914 \mathrm{~mm} \times 381 \mathrm{~mm}$ were tested. The smaller panels were found to cease sustained flaming for separations of more than $51 \mathrm{~mm}$; for the larger panels around $127 \mathrm{~mm}$. Given the separation, radiation is the dominant mode of heat transfer. The view factors between the two panels can be calculated using expressions from [76, 77] as 0.66 and 0.65 respectively. Assuming a similar flame temperature, this view factor corresponds to a critical radiant heat flux for sustained flaming. The effect of airflow was also explored; as expected, a greater airflow resulted in longer times to ignition due to initial cooling, but once ignited resulted in more complete combustion due to improved mixing conditions. For this reason, 
when these tests were repeated on horizontal panels, the burning was much less vigorous.

Hottel [37] tested $25 \mathrm{~mm} \times 152 \mathrm{~mm} \times 305 \mathrm{~mm}$ spruce samples, conditioned at approximately $32 \%$ relative humidity, in a vertical configuration under radiant heating. It was found that an incident heat flux of $31.5 \mathrm{~kW} / \mathrm{m}^{2}$ was required to sustain a flame for more than $10 \mathrm{~min}$ (the heat flux was reduced to this value after ignition). Further experiments, in which the irradiation was ceased after ignition, demonstrated that samples ignited at lower heat fluxes tended to take longer to extinguish, which was attributed to a greater heating time and thus shallower thermal gradient, as char will form more slowly allowing more conduction further into the sample, thus reducing the conductive heat losses later in the experiment. Critical heat fluxes for ignition were around $28 \mathrm{~kW} / \mathrm{m}^{2}$ (piloted) and $71 \mathrm{~kW} / \mathrm{m}^{2}$ (unpiloted), which are significantly higher than those from other authors. This difference is attributed to the apparatus and/or test method used.

Inghelbrecht [7] tested $100 \mathrm{~mm} \times 100 \mathrm{~mm}$ CLT radiata pine $\left(\rho=635 \mathrm{~kg} / \mathrm{m}^{3}\right)$ samples $72 \mathrm{~mm}$ thick and hoop pine $\left(\rho=540 \mathrm{~kg} / \mathrm{m}^{3}\right)$ samples $96 \mathrm{~mm}$ thick, Gympie messmate (an Australian hardwood) glulam samples ( $\left.\rho=823 \mathrm{~kg} / \mathrm{m}^{3}\right)$ $60 \mathrm{~mm}$ thick, and solid hoop pine $\left(\rho=560 \mathrm{~kg} / \mathrm{m}^{3}\right)$ samples $70 \mathrm{~mm}$ thick in a vertical orientation in a cone calorimeter under imposed heat fluxes of 25, 40, 60, and $80 \mathrm{~kW} / \mathrm{m}^{2}$ applied perpendicular to the grain for exposure times of $10,20,30$, and $60 \mathrm{~min}$. Temperature was recorded using K-type thermocouples at depths of $5 \mathrm{~mm}, 15 \mathrm{~mm}, 25 \mathrm{~mm}, 35 \mathrm{~mm}$, and $45 \mathrm{~mm}$ from the heated surface; additionally mass loss was recorded throughout the experiments. For the experiments at $25 \mathrm{~kW} / \mathrm{m}^{2}$, delamination occurred followed by flaming ignition. Upon removal of the external heat flux, the $80 \mathrm{~kW} / \mathrm{m}^{2}$ samples (10 min exposure) extinguished after $2.5 \mathrm{~min}$. The $25 \mathrm{~kW} / \mathrm{m}^{2}$ samples (60 min exposure) had delayed auto-extinction due to the delaminated first layer leaning against the rest of the sample serving as additional fuel. A decrease in mass flux will result in flameout. The critical mass flux from this work can be approximated by Eq. (9):

$$
\dot{m}_{c r, e x}^{\prime \prime}=\frac{h_{c}}{C_{p}} \ln (1+B)
$$

which typically gives a critical mass flux of 4 to $5 \mathrm{~g} / \mathrm{m}^{2} \mathrm{~s}$, where $B$ is Spalding's Bnumber, which is the ratio of the heat produced per molecule burning to the heat required to vaporise an additional molecule. Thus if $B>1$, burning will be sustained, but if $B<1$, burning will cease.

\section{Properties Influencing the Burning of Wood}

The above phenomena are all heavily influenced by material properties and the testing conditions. To enable the fire safe use of engineered timber, it is necessary to obtain a better understanding of the relative effects of various material, system, and fire properties on the burning behaviour. Throughout the literature, this is typically characterised by "charring rate"-whilst it is known that upon exposure 
to heat, timber undergoes an initial "peak" charring rate before reaching a steadystate value [78]. The average charring rates presented in this section are all averaged over the entire fire duration - thus including this initial peak. The influence of this peak diminishes with increasing fire duration.

\subsection{Material Properties}

3.1.1. Density Charring rate is demonstrated to be strongly dependent on density $[4,5,11,13,15,17,20,46,64,67,69,79-91]$, with various charring models [67, $69,82]$ using density as a key variable. In general, it has been found that charring rate under exposure to the standard temperature-time curve [92] (to which the majority of recent work has been undertaken) can vary from around $0.8 \mathrm{~mm} / \mathrm{min}$ for light, dry softwoods, decreasing to 0.4 to $0.5 \mathrm{~mm} / \mathrm{min}$ for dense, moist hardwoods [46, 84, 91], with $0.6 \mathrm{~mm} / \mathrm{min}$ being a reasonable average value [84, 91]. Decreasing density occurs due to an increase in void volume, reducing thermal conductivity and thus producing localised heating and heat accumulation, resulting in increased flame spread rates [82].

Lizhong et al. [85] and Tran and White [64] tested small-scale samples $(100 \mathrm{~mm} \times 100 \mathrm{~mm}$ and $150 \mathrm{~mm} \times 150 \mathrm{~mm}$ surface area respectively) under radiant heat exposure to determine the dependency of charring rate on density and various other factors. Both experimental series found a general trend of decreasing charring rate with increasing density.

Lizhong et al. [85] tested horizontal samples of paulownia $\left(\rho=260 \mathrm{~kg} / \mathrm{m}^{3}\right)$, toon $\left(\rho=530 \mathrm{~kg} / \mathrm{m}^{3}\right)$, and elm $\left(\rho=590 \mathrm{~kg} / \mathrm{m}^{3}\right)$ in a radiation platform to linearly increasing heat fluxes, ranging from $0.07 \mathrm{~kW} / \mathrm{m}^{2} \mathrm{~s}$ to $0.425 \mathrm{~kW} / \mathrm{m}^{2} \mathrm{~s}$, and constant heat fluxes of 40 and $60 \mathrm{~kW} / \mathrm{m}^{2}$. Charring rates were determined by temperature measurements using K-type thermocouples at $0 \mathrm{~mm}, 2 \mathrm{~mm}, 6 \mathrm{~mm}$, and $10 \mathrm{~mm}$ from the exposed surface. In both cases charring rate was found to increase with decreasing density, such that $\beta \propto \rho^{-0.76}$ for linearly increasing heat fluxes, and $\beta \propto \rho^{-0.5}$ for constant heat fluxes.

Tran and White [64] tested vertical samples of red oak $\left(\rho=660 \mathrm{~kg} / \mathrm{m}^{3}\right)$, redwood $\left(\rho=312 \mathrm{~kg} / \mathrm{m}^{3}\right)$, southern pine $\left(\rho=508 \mathrm{~kg} / \mathrm{m}^{3}\right)$, and basswood $\left(\rho=420 \mathrm{~kg} / \mathrm{m}^{3}\right)$ in a modified Ohio State University (OSU) apparatus to constant heat fluxes of nominally $15,25,35$, and $50 \mathrm{~kW} / \mathrm{m}^{2}$. Charring rates were determined from mass loss data using Eq. (10):

$$
\beta=\frac{\dot{m}^{\prime \prime}}{\rho_{w}}
$$

Of the species tested, redwood and southern pine were softwoods, and red oak and basswood were hardwoods. For all heat fluxes, redwood charred around $20 \%$ faster than southern pine. Similarly, basswood samples charred approximately $60 \%$ faster than red oak samples. Interestingly, the trend across all four samples was inconsistent, with basswood samples charring consistently faster than red oak, despite having a higher density. This is likely due to the impact of other factors such as permeability and species (see Sects. 3.1.3 and 3.1.4, respectively). 
Furnace tests $[27,67,69,82,83,89,93,94]$ have also explored the effects of density on charring rate. Of these, White [83], White and Nordheim [69] and Schaffer [82] tested to the ASTM E 119 standard temperature-time curve [95]; Hugi et al. [27], Njankouo et al. [89], Frangi and Fontana [93], and Cedering [94] tested to the ISO 834 standard temperature-time curve [92]. Schaffer [82] also tested to 'constant' furnace temperatures of $538^{\circ} \mathrm{C}, 816^{\circ} \mathrm{C}$, and $927^{\circ} \mathrm{C}$. In each case, charring rates were determined from the position of the $300^{\circ} \mathrm{C}$ isotherm, except by Frangi and Fontana [93] who determined average charring rates by measuring the residual sample height after each test. The majority of authors found that charring rates decreased with increasing density, as expected and as seen from experiments under direct radiant heating. Some authors however [27, 93, 94], found no correlation between density and charring rate. In the case of Frangi and Fontana [93] and Cedering [94], this is likely due to the small range of densities $\left(\sim 125 \mathrm{~kg} / \mathrm{m}^{3}\right)$ over which tests were performed. Hugi et al. [27], however, tested 12 species with densities of 350 to $750 \mathrm{~kg} / \mathrm{m}^{3}$ yet no strong correlation was observed-species, in particular permeability, appeared to have a greater effect.

Njankouo et al. [89] tested spruce $\left(\rho=478 \mathrm{~kg} / \mathrm{m}^{3}\right)$, fir $\left(\rho=421 \mathrm{~kg} / \mathrm{m}^{3}\right)$, oak $\left(\rho=557 \mathrm{~kg} / \mathrm{m}^{3}\right)$, azobe $\left(\rho=1038 \mathrm{~kg} / \mathrm{m}^{3}\right)$, afzelia $\left(\rho=860 \mathrm{~kg} / \mathrm{m}^{3}\right)$, balau $\left(\rho=962 \mathrm{~kg} / \mathrm{m}^{3}\right)$, bilinga $\left(\rho=692 \mathrm{~kg} / \mathrm{m}^{3}\right)$, meranti $\left(\rho=522 \mathrm{~kg} / \mathrm{m}^{3}\right)$, merbau $\left(\rho=779 \mathrm{~kg} / \mathrm{m}^{3}\right)$, and wenge $\left(\rho=923 \mathrm{~kg} / \mathrm{m}^{3}\right)$ in a vertical furnace, with samples inserted in a frame with 20 holes measuring $280 \times 170 \mathrm{~mm}$ and subjected to onesided heating. Charring rate was found to decrease from around $0.60 \mathrm{~mm} / \mathrm{min}$ at $500 \mathrm{~kg} / \mathrm{m}^{3}$ to around $0.40 \mathrm{~mm} / \mathrm{min}$ at $1000 \mathrm{~kg} / \mathrm{m}^{3}$.

White and Nordheim [69] tested five $230 \mathrm{~mm} \times 510 \mathrm{~mm} \times 63 \mathrm{~mm}$ boards of eight different wood species (Engelmass spruce, western red cedar, southern pine, redwood, hard maple, yellow poplar, red oak, and basswood). The southern pine samples consisted of seven lamellae where the others had five. Several charring models were proposed based on the results obtained: the standard $t=m x_{c}$, (where $x_{c}$ is the char depth and $m$ is the reciprocal of the charring rate); $t=m x_{c}-b$ which takes into account the faster initial charring rate; $t=d x_{c}+g x_{c}^{2}$; and the preferred model of the form $\ln t=\ln m+a \ln x_{c}$ or $t=m x_{c}^{a}$, in which $a$ was found to be equal to approximately 1.23, and $\mathrm{m}$ was species-dependent, given by Eq. (11):

$$
m=0.162+0.000809 \rho+1.07 w+0.0689 c-0.00000655 \rho d-0.0024 c d
$$

where $c$ is a (dimensionless) softwood/hardwood classification (1 for softwoods, -1 for hardwoods), and $d$ a factor representing permeability (in $\mathrm{mm}$ ), discussed in Sect. 3.1.3. An alternative expression for $m$ is given in Eq. (12):

$$
m=-0.147+0.000564 \rho+1.21 w+0.532 f_{C}
$$

where $f_{C}$ is the char contraction factor, given in Eq. (13):

$$
f_{C}=0.732-0.00423 d+0.203 c-0.00164 c d-0.00027 \rho c
$$


Equation (11) gives a coefficient of determination of 0.764, and Eq. (12) 0.755. It can be seen again that charring rate decreases with increasing density. For a parameter set giving a charring rate of $0.60 \mathrm{~mm} / \mathrm{min}$ with a density of $500 \mathrm{~kg} / \mathrm{m}^{3}$, using Eq. (11), this reduces to $0.43 \mathrm{~mm} / \mathrm{min}$ with a density of $1000 \mathrm{~kg} / \mathrm{m}^{3}$, giving similar results to those in [89]. All of these equations however are empirical, and thus have limited predictive value.

Schaffer [82] tested Douglas fir, southern pine, and white oak samples in a vertical furnace. Samples were conditioned at $27^{\circ} \mathrm{C}$ at $30 \%, 65 \%$, and $80 \%$ relative humidity to vary moisture contents to around $6 \%, 12 \%$, and $18 \%$. Samples were tested with the grain parallel and normal to the fire-exposed surface. The total sample size was $254 \mathrm{~mm} \times 508 \mathrm{~mm} \times 76 \mathrm{~mm}$, formed of lamellae joined together by a phenol-resorcinol adhesive which was found to 'resist' delamination (a phenomenon in which the outermost lamella or part(s) thereof detach from the underlying lamellae) under the conditions tested. From the test data, the expression in Eq. (14) was derived:

$$
m=(a+b w) \rho_{w}+c
$$

where $a, b$ and $c$ are empirical species-dependent constants. This is similar to the expressions from White and Nordheim [69], again suggesting that charring rate decreases with increasing density, which was attributed to a greater mass available to absorb energy. Additionally, crack and fissure size and formation were found to vary with density.

White [83] tested various composite timber products - Laminated Strand Lumber (LSL), produced by gluing strands of wood together; Laminated Veneer Lumber (LVL); and Parallel Strand Lumber (PSL), formed from $19 \mathrm{~mm}$ strands of timber aligned and then pressed together with adhesives. Results were compared with the models presented in [69], with $m$ calculated as in Eq. (14), predicting charring rate to within $12 \%$.

Lau et al. [67] tested to a constant furnace temperature of $500^{\circ} \mathrm{C}$. Whilst they did not explicitly explore the effects of charring rate on density, they observed charring rates around knots to be lower due to higher density.

Overall, it can be concluded that samples with higher density will generally char more slowly due to the greater mass of material to pyrolyse; thus more energy is required to fuel this endothermic process. This is illustrated in Fig. 2, which shows the charring rate and density for all standard temperature-time curve tests discussed. From the tests and experiments discussed above, it can be seen that this only has a significant effect over wide density ranges, and thus is unlikely to be the governing factor in design, where typical softwoods used in construction are unlikely to vary in density by more than about $\pm 200 \mathrm{~kg} / \mathrm{m}^{3}$. Additionally, the density variation within an individual sample will often be sufficiently high (around $\pm 20 \mathrm{~kg} / \mathrm{m}^{3}$ for a beam tested in a typical furnace [96]) that predicting charring rate based on a global density value will be meaningless. Frangi and Fontana [93] and Cedering [94] did not find any dependency on density over a range of around $\pm 125 \mathrm{~kg} / \mathrm{m}^{3}$-indeed based on the results of [89] and the models in [69], over this range, it would be expected that the corresponding variation in 


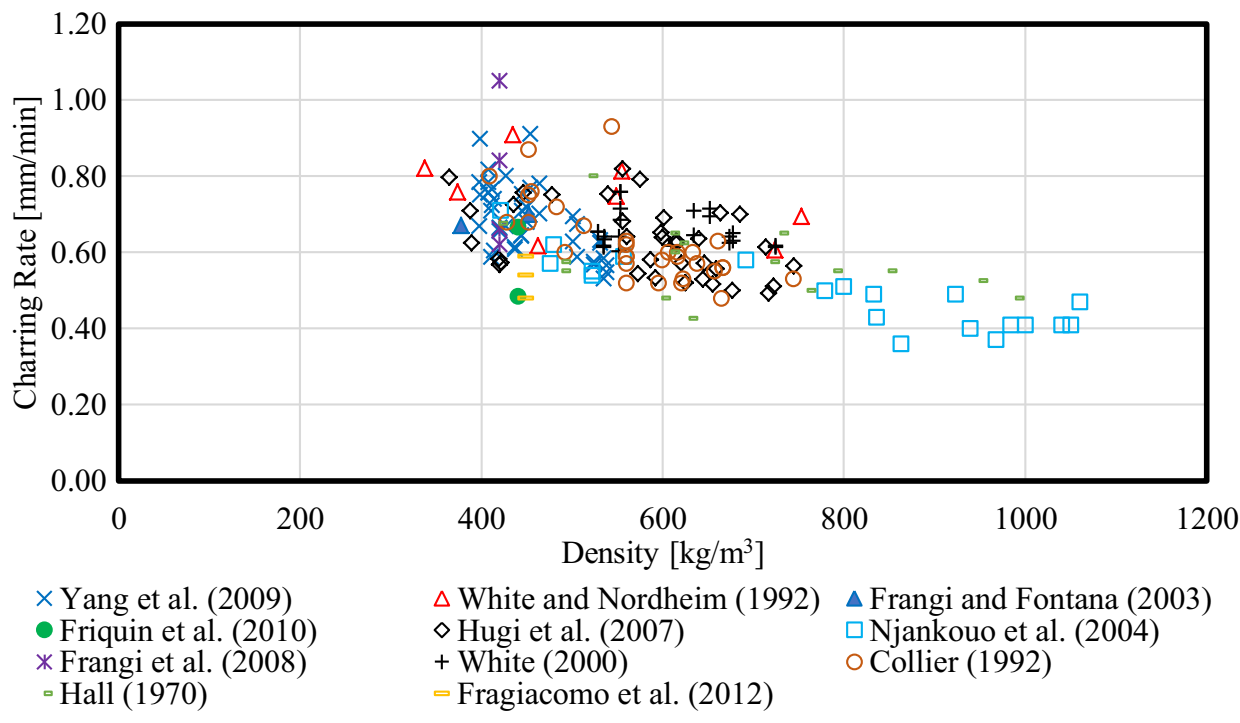

\section{Figure 2. Charring rate versus density plot for standard temperature-time curve tests reviewed herein.}

charring rate would be just $0.05 \mathrm{~mm} / \mathrm{min}$, which is less than the scatter in the results.

In a review on timber charring rates, Friquin [5] also found that charring rates decreased with increasing density. Some authors found charring rates varied strongly with density, whereas some tests found no variation of charring rate with density, perhaps due to variations within the sample or to the small range of densities tested. Samples with lower density typically had lower thermal conductivity, thus resulting in a faster temperature rise at the surface, thus pyrolysing and charring earlier. Conversely, higher density samples had higher through-thickness temperatures, and pyrolysed more quickly due to shallower thermal gradients.

Furthermore, as noted by Friquin [5], mass loss rates increase for denser samples. This can be easily calculated from charring rates via Eq. (10), and the results are shown in Fig. 3. It can be seen that whilst charring rate weakly decreases with density, mass loss rate, and thus overall pyrolysis, weakly increases. Thus, the contribution of flammable vapours from denser samples will be greater.

3.1.2. Moisture Content The presence of moisture is widely acknowledged as retarding pyrolysis $[5,12,13,16,18,20,21,39,67,69,79,82,84,86,90,94,97$, 98] due to a heat sink effect - the greater the moisture content, the greater the energy required to evaporate the water, and thus the less energy available for pyrolysis.

Mikkola [12], Moghtaderi et al. [39], Shen et al. [21], and McAllister et al. [41] tested small-scale samples $(100 \mathrm{~mm} \times 100 \mathrm{~mm}$, except McAllister et al. [41] who used $90 \mathrm{~mm} \times 90 \mathrm{~mm}$ ) under radiant heat exposure to determine the effects of 


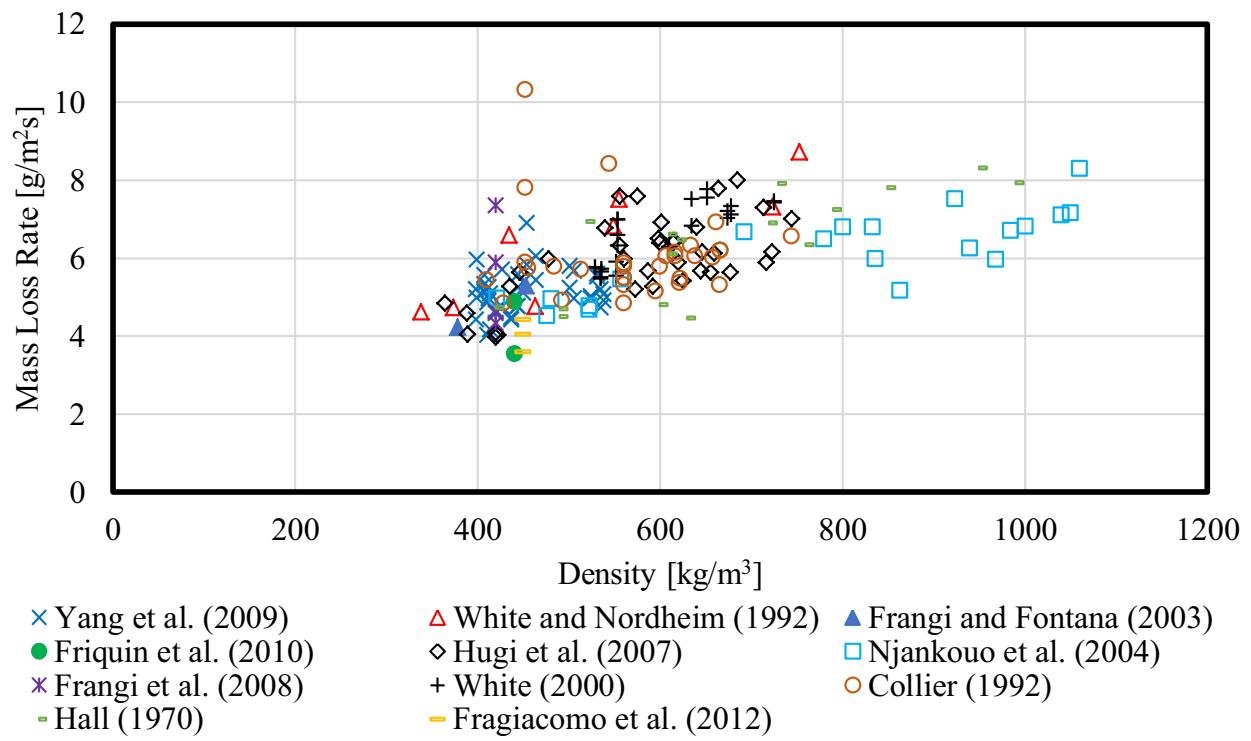

\section{Figure 3. Mass loss rate (as calculated using Eq. 10) versus density plot for standard temperature-time curve tests reviewed herein.}

moisture content. All recorded different specific outcomes (e.g. charring rate, time to ignition, mass loss rate), but all unsurprisingly observed retarded pyrolysis with increasing moisture content. Mikkola [12] tested pine $\left(\rho=560 \mathrm{~kg} / \mathrm{m}^{3}\right)$, spruce $\left(\rho=490 \mathrm{~kg} / \mathrm{m}^{3}\right)$, and LVL $\left(\rho=520 \mathrm{~kg} / \mathrm{m}^{3}\right)$ samples with moisture contents varying from $0 \%$ to $20 \%$ in a cone calorimeter at heat fluxes from $20 \mathrm{~kW} / \mathrm{m}^{2}$ to $75 \mathrm{~kW} / \mathrm{m}^{2}$. Temperature was recorded at various depths throughout the sample, and charring rate calculated from this, assuming a charring temperature of $360^{\circ} \mathrm{C}$, $20 \%$ higher than other researchers. For an incident heat flux of $50 \mathrm{~kW} / \mathrm{m}^{2}$, charring rate varied from an average of $1.07 \mathrm{~mm} / \mathrm{min}$ at $0 \%$ moisture, decreasing to $0.80 \mathrm{~mm} / \mathrm{min}$ at $10 \%$, to $0.64 \mathrm{~mm} / \mathrm{min}$ at $20 \%$. From these results, Mikkola presents the empirical relationship in Eq. (15):

$$
\beta \propto \frac{1}{1+2.5 w}
$$

where $w$ is moisture content $(\mathrm{kg} / \mathrm{kg})$. This assumes a strong dependency on moisture content, with dry wood charring $25 \%$ faster than wood with $10 \%$ moisture content, and $50 \%$ faster than wood with $20 \%$ moisture content.

Shen et al. [21] tested vertically oriented birch samples $\left(\rho=740 \mathrm{~kg} / \mathrm{m}^{3}\right)$ with moisture contents of $5 \%, 15 \%$, and $26 \%$ to $40 \mathrm{~kW} / \mathrm{m}^{2}$ in a cone calorimeter. Temperature was recorded throughout the tests using K-type thermocouples at $1 \mathrm{~mm}, 7 \mathrm{~mm}$, and $14 \mathrm{~mm}$ below the exposed surface, as well as mass loss rate. Variation in surface temperature was explored, and the time to reach $350^{\circ} \mathrm{C}$ was 
recorded - this being approximately $30 \mathrm{~s}, 50 \mathrm{~s}$, and $60 \mathrm{~s}$ for moisture contents of $5 \%, 15 \%$, and $26 \%$, respectively.

McAllister et al. [41] tested poplar samples in a $90 \mathrm{~mm} \times 250 \mathrm{~mm} \times 600 \mathrm{~mm}$ wind tunnel capable of varying airflow velocity from $0.8 \mathrm{~m} / \mathrm{s}$ to $1.6 \mathrm{~m} / \mathrm{s}$. Poplar has a consistent grain, low number of knots, and a high cellulose content. Moisture contents of $0 \%, 8 \%$, and $18.5 \%$ were tested at heat fluxes from $20 \mathrm{~kW} / \mathrm{m}^{2}$ to $50 \mathrm{~kW} / \mathrm{m}^{2}$. The emitter used in these experiments has shorter emission peaks than in a typical fire, of 1.03 to $1.30 \mu \mathrm{m}$ compared to 1.97 to $2.28 \mu \mathrm{m}$, so samples were darkened to increase absorptivity. For a $50 \mathrm{~kW} / \mathrm{m}^{2}$ heat flux imposed on a sample with $18.5 \%$ moisture content with an airflow of $1 \mathrm{~m} / \mathrm{s}$, critical mass flux was found to be $2.83 \mathrm{~g} / \mathrm{m}^{2} \mathrm{~s}$ and $3.12 \mathrm{~g} / \mathrm{m}^{2} \mathrm{~s}$ for flashpoint and firepoint, respectively. Critical mass flux was found to increase with moisture content, with the overall range being from $1.31 \mathrm{~g} / \mathrm{m}^{2} \mathrm{~s}$ to $2.98 \mathrm{~g} / \mathrm{m}^{2} \mathrm{~s}$. With increased moisture content, water is still being evaporated at ignition, absorbing heat, and thus requiring a greater mass flux.

Moghtaderi et al. [39] tested Pacific maple $\left(\rho=544 \mathrm{~kg} / \mathrm{m}^{3}\right)$, sugar pine $\left(\rho=430 \mathrm{~kg} / \mathrm{m}^{3}\right)$, and radiata pine $\left(\rho=465 \mathrm{~kg} / \mathrm{m}^{3}\right)$ samples in a cone calorimeter to heat fluxes varying from $14 \mathrm{~kW} / \mathrm{m}^{2}$ to $65 \mathrm{~kW} / \mathrm{m}^{2}$. Average moisture content was 10 to $12 \%$. Radiata pine samples were conditioned to achieve moisture contents of $0 \%, 15 \%, 22 \%$, and $30 \%$. Times to ignition increased substantially with increased moisture content. At $20 \mathrm{~kW} / \mathrm{m}^{2}$, the ignition time increased from $179 \mathrm{~s}$ at $0 \%$ moisture to $540 \mathrm{~s}$ at $30 \%$ moisture, and at $60 \mathrm{~kW} / \mathrm{m}^{2}$, increased from $3 \mathrm{~s}$ to $11 \mathrm{~s}$. Mass flux at ignition also increased slightly as moisture content increased, and surface temperature at ignition increased with moisture content, due to the increased heating time.

Di Blasi et al. [16] tested $40 \mathrm{~mm}$ diameter and length beech cylinders $\left(\rho=728 \mathrm{~kg} / \mathrm{m}^{3}\right.$ to $\left.911 \mathrm{~kg} / \mathrm{m}^{3}\right)$ in a radiant furnace with a $60 \mathrm{~mm}$ diameter quartz reactor. Mass loss was recorded throughout some tests, whilst in others temperature was recorded by five K-type thermocouples along the radius. Moisture content was varied from $0 \%$ to $50 \%$; it was found that increased moisture content significantly increased the time to maximum mass loss rate-from c. $1400 \mathrm{~s}$ at $0 \%$ moisture content, to c. $2300 \mathrm{~s}$ at $11 \%$, to c. $3100 \mathrm{~s}$ at $29 \%$, to c. $3700 \mathrm{~s}$ at $49 \%$.

Bamford's tests [18], discussed previously in Sect. 2.4, found that for two identical $229 \mathrm{~mm}$ square panels opposite each other, ignition times were $9 \mathrm{~min}$ and 3 min for moisture contents of $14 \%$ and $6 \%$ respectively. For single panels heated on both sides, ignition time reduced from $12 \mathrm{~min}$ to $10 \mathrm{~min}$ to $8 \mathrm{~min}$, with reductions in moisture content from $12 \%$ to $6.5 \%$ to $1 \%$.

Furnace tests $[69,84,89,94]$ have also been used to explore the effects of moisture content on charring rate. Of these, White and Nordheim [69] tested to the ASTM E 119 standard temperature-time curve [95]; Njankouo et al. [89] and Cedering [94] tested to the ISO 834 standard temperature-time curve [92]; and Collier [84] tested to the AS 1530.4 standard temperature-time curve [99] - either 60 min exposure, $30 \mathrm{~min}$ exposure, or $30 \mathrm{~min}$ exposure starting at the $31 \mathrm{st}$ minute. All test series found that increasing moisture content led to reduced charring rates, although there is disagreement as to the precise effects. 
The tests undertaken by Njankouo et al. [89], discussed in Sect. 3.1.1, had moisture contents varying from $9 \%$ to $20 \%$. Generally, charring rate was found to decrease linearly from around $0.6 \mathrm{~mm} / \mathrm{min}$ at $9 \%$ moisture content to $0.37 \mathrm{~mm} /$ min at $20 \%$, but with three or four outliers, suggesting other factors (such as species or density) may be contributing and preventing a definite conclusion.

Collier [84] reports that moisture content significantly affects charring rate through several different mechanisms, but does not state what these are. Some effects oppose each other (such as the driving of moisture deeper into the sample) but overall, increases in moisture content reduce charring rate. As such, charring rates can increase by up to $25 \%$ for completely dry timber, however this is of little importance in design, as timber will reach its equilibrium moisture content (typically assumed to be around 10-12\%). Collier's tests on radiata pine showed charring rates decreasing from $0.82 \pm 0.10 \mathrm{~mm} / \mathrm{min}$ at $0 \%$ moisture content, to $0.59 \pm 0.01 \mathrm{~mm} / \mathrm{min}$ at $16 \%$ moisture content, to $0.53 \mathrm{~mm} / \mathrm{min}$ at $20 \%$ moisture content.

White and Nordheim's [69] tested eight species at four different moisture contents each: $6 \%, 9 \%, 11 \%$, and $16 \%$. From this, they found that charring rate decreased with increasing moisture content, leading to the expressions in Eqs. (11) and (12). This again gives a moderate dependency on moisture content, with dry wood charring $14 \%$ faster than wood with $10 \%$ moisture content, and $28 \%$ faster than wood with $20 \%$ moisture content, significantly less of an influence than suggested by Eq. (15) [12].

Cedering [94] tested three solid timber walls of dimensions $40 \mathrm{~mm} \times 140 \mathrm{~mm} \times$ $1000 \mathrm{~mm}$ formed of 55 to 60 timber studs of Norwegian spruce with varying density and moisture content, to the standard temperature-time curve in a furnace to varying oxygen contents. The samples were orientated vertically. The moisture content of the samples was controlled to give values of $6 \%, 12 \%$, or $18 \%$. The average charring rates across all oxygen contents decreased from $0.70 \mathrm{~mm} / \mathrm{min}$ at $6 \%$ moisture content, to $0.68 \mathrm{~mm} / \mathrm{min}$ at $12 \%$ moisture content, to $0.64 \mathrm{~mm} / \mathrm{min}$ at $18 \%$ moisture content. This gives an average decrease in charring rate of just $4 \%$ over a $6 \%$ moisture content increase, compared with the $11 \%$ given by Eq. (15) [12], or 7\% given by Eq. (11) [69]. This small increase could be partially attributed to the fact that timber samples of varying moisture contents were placed in the furnace simultaneously, resulting in unpredictable moisture flows between and in front of samples, corrupting results.

It can be seen that whilst there is strong agreement that increasing moisture content leads to a reduced charring rate due to the latent heat of evaporation of the moisture, there is generally poor agreement as to how much of an effect this has. This is illustrated in Fig. 4, which shows the charring rate and moisture content for all standard temperature-time curve tests discussed. There is poor agreement between tests, although a weak general downwards trend can be distinguished. This is most likely due to the presence of other variables such as density and species dominating the effects on charring rate.

Friquin [5] reports that moisture content has a significant effect on charring rate, with charring rate decreasing with increasing moisture content due to more energy being needed to evaporate the water. Water vapour also serves to delay 


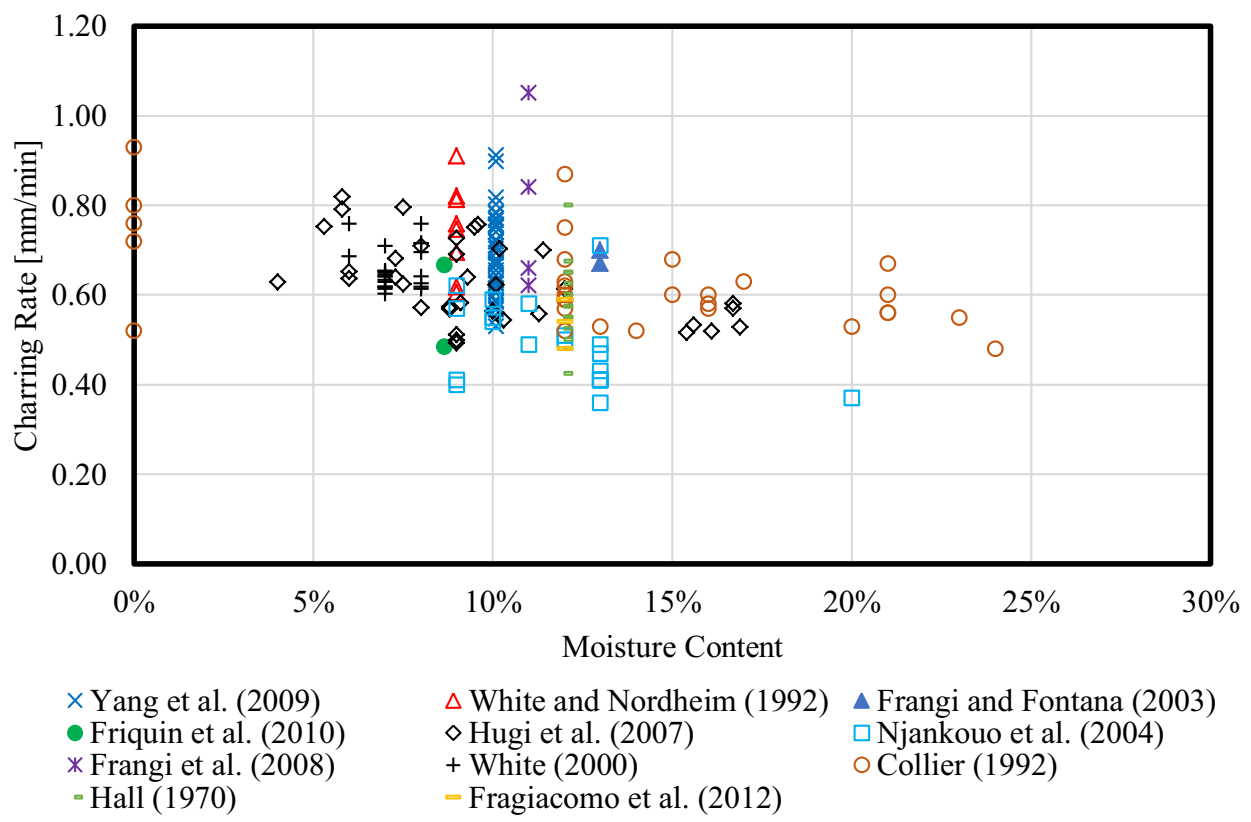
Figure 4. Charring rate versus moisture content plot for standard
temperature-time curve tests reviewed herein.

ignition time, and delay and dilute combustible gases. Further, Babrauskas [97] notes that charring rate at $20 \%$ moisture content can be $8.3 \%$ lower than charring rate at $8 \%$ moisture content. This is a much smaller difference than the $20 \%$ reduction given by Eq. (15) [12], or the 13\% reduction from Eq. (11) [69].

As with density, the effects of moisture content are unlikely to be of large practical importance, as moisture content is not a variable that can be controlled - it will be dictated by ambient temperature and relative humidity, which in turn will depend on geographical location [100] and building management practice. The equilibrium moisture content of wood, in $\%$, defined as the ratio of water mass to dry mass, can be found from Eq. (16) [100].

$$
w=\frac{1800}{a}\left(\frac{b h}{1-b h}+\frac{b c h+2 b^{2} c d h^{2}}{1+b c h+b^{2} c d h^{2}}\right)
$$

where

$$
\begin{aligned}
& a=349+1.29 T+0.0135 T^{2} \\
& b=0.805+0.000736 T-0.00000273 T^{2}
\end{aligned}
$$




$$
\begin{aligned}
& c=6.27-0.00938 T-0.000303 T^{2} \\
& d=1.91+0.0407 T-0.000293 T^{2}
\end{aligned}
$$

This gives typical values around 18 to $19 \%$ in winter and 13 to $15 \%$ in summer in the UK. It should be noted that Eq. (16) does not consider different species of wood, which is an obvious shortcoming, since different wood species will have different chemical and anatomical make-ups, allowing different levels of moisture absorption, however it is relatively easy to measure equilibrium moisture content of timber, and can be determined using standards such as ASTM D 4442 [101]. It should also be noted that this is based on outdoor conditions, and thus should be applied with caution for interior conditions.

3.1.3. Permeability Permeability affects charring rate $[5,20,27,64,67,69,79,80$, 84]. This is largely due to grain direction, as permeability along the grain is around four orders of magnitude higher than that across the grain $[5,84,102]$. The effect of grain direction is discussed further in Sect. 3.2.3. Increased permeability allows an increased flow of volatiles, thus contributing to faster pyrolysis.

Tran and White [64] tested redwood, southern pine, red oak, and basswood under a radiant panel, with permeability measured transverse to the grain through the penetration depth of copper chrome arsenate (CCA). This is applied as parameter $d$ in Eqs. (11) and (13), giving $d=4,31,3$, and $30 \mathrm{~mm}$ for redwood, southern pine, red oak, and basswood, respectively. No obvious trend of charring rate was observed with permeability alone, however when considered alongside density, it may be suggested that increased permeability increases charring rate, however too many variables were examined in these experiments to allow meaningful isolation of any of them.

Hugi et al. [27] and White and Nordheim [69] explored the effects of permeability on charring rate under exposure to ISO 834 and ASTM E 119 respectively. Hugi et al. [27] calculated permeability using a coefficient (detailed below), whereas White and Nordheim [69] used the method set forth by Tran and White [64]. Both sets of authors found increasing charring rate with increasing permeability.

Hugi et al. [27] tested 12 wood species of dimensions $1000 \mathrm{~mm} \times 90 \mathrm{~mm} \times 45 \mathrm{~mm}$ (abachi, abura, maple, beech, oak, ash, spruce, koto, meranti dark red, meranti light red, sipo, and fir) at tree ring orientations of $0^{\circ}$ (tangential), $45^{\circ}$, and $90^{\circ}$ (radial). Charring rate was calculated by cutting samples in two after the test and measuring the residual depth over five locations for each sample. This was compared with permeability; the coefficient of permeability was calculated by Eq. (17):

$$
k=\frac{\omega V g d}{R A T_{a b s} t} \ln \frac{P(0)}{P(t)}
$$




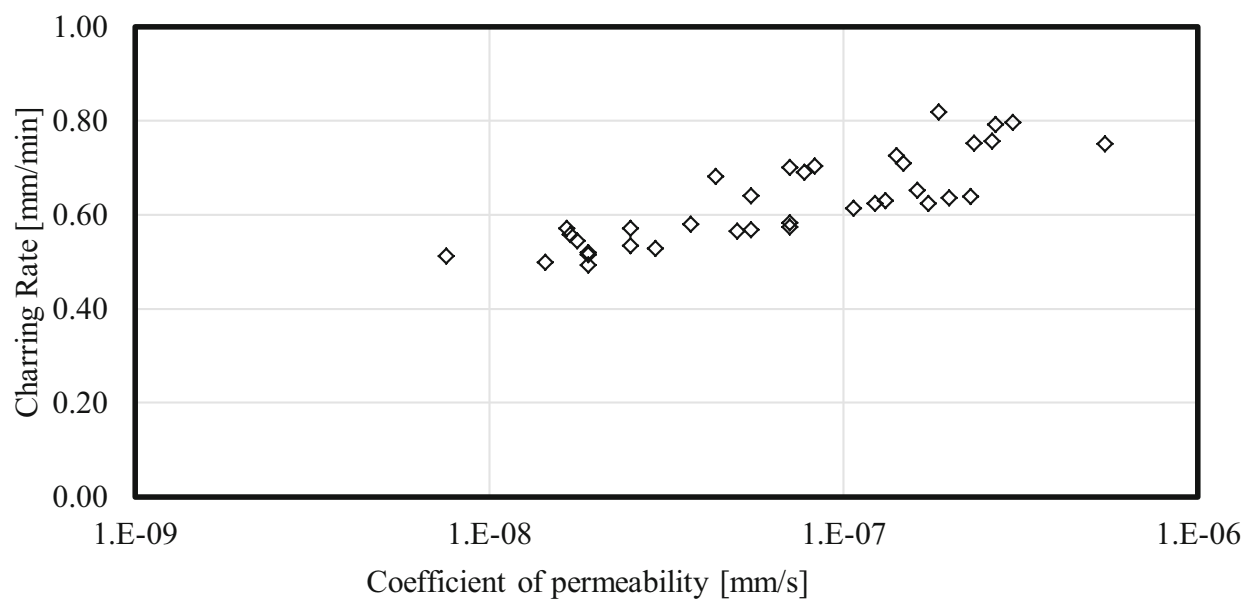

\section{Figure 5. Charring rate versus coefficient of permeability plot for tests performed by Hugi et al. [27].}

where $\omega$ is the molar mass of gaseous oxygen $(\mathrm{g} / \mathrm{mol}), V$ is the volume of the pressure cylinder $\left(\mathrm{m}^{3}\right), A$ and $d$ are the sample cross-sectional area $\left(\mathrm{m}^{2}\right)$ and thickness $(\mathrm{m})$ respectively, and $P$ is the pressure $(\mathrm{kPa})$. The oxygen permeability index was then taken as the negative logarithm of this value. Charring rate was found to have a positive linear relationship with oxygen permeability index, suggesting that charring rate increases with increased permeability.

White and Nordheim [69], (discussed in Sect. 3.1.1) measured CCA penetration depths of $3 \mathrm{~mm}$ for Engelmann spruce, western red cedar, and red oak; $4 \mathrm{~mm}$ for redwood; $5 \mathrm{~mm}$ for yellow poplar; $30 \mathrm{~mm}$ for basswood; $31 \mathrm{~mm}$ for southern pine; and $47 \mathrm{~mm}$ for hard maple. As shown by Eqs. (11) and (13), this gives a charring rate increasing with increasing permeability.

In general, there is good agreement that charring rate increases with increasing permeability, however Tran and White [64] did not observe any obvious trend. Data from Hugi et al. [27] is shown in Fig. 5 to allow a visual observation of the effects of permeability on charring rate.

3.1.4. Species Another significant factor affecting pyrolysis rate is the species of the wood $[5,15-17,20,46,64,67,69,79-82,84,86,89,93,103]$. Whilst the species will affect factors discussed earlier such as density, moisture content, and permeability, there will also be additional factors specific to a species, such as chemical composition $[5,20,64,67,79,84]$ (primarily lignin content $[5,64,67]$ ) and anatomy [5,69] which influence the rate of pyrolysis.

Di Blasi et al. [103], Shen et al. [21] and Lizhong et al. [104] explored the effects of species on thermal response under radiant heat exposure. The experiments are described in Sects. 2.2 and 3.1.2 All authors observed a species dependence, but the dependency found by Lizhong et al. [104] was very small. 


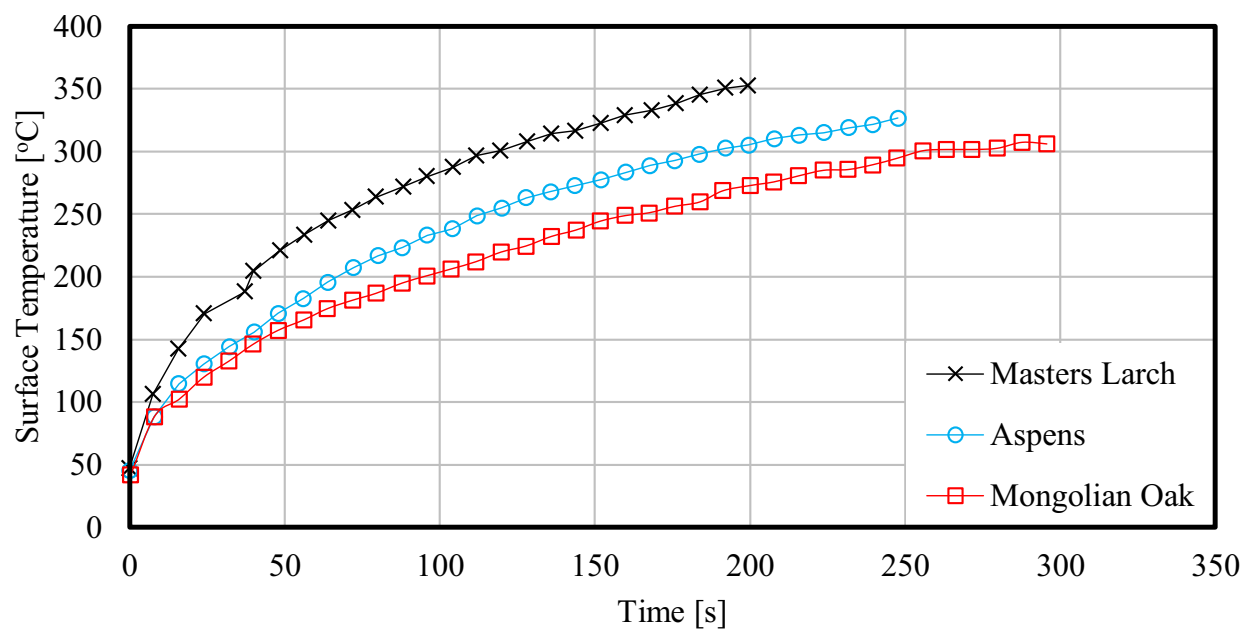

\section{Figure 6. Experimental temperature histories for Mongolian oak, aspens, and Masters Larch under a heat flux of $20 \mathrm{~kW} / \mathrm{m}^{2}$ (data from [21]).}

Di Blasi et al. [103] found pyrolysis temperature to be lowest for chestnut (due to its higher proportions of hemicelluloses), then Douglas fir, redwood, pine, and highest for beech. Char yields followed an opposing trend, being highest for chestnut, then redwood, Douglas fir, pine, and lowest for beech. Lower lignin contents were found to yield more carbon dioxide, as expected.

Shen et al. [21] conducted further experiments on Mongolian oak $\left(\rho=888 \mathrm{~kg} / \mathrm{m}^{3}\right)$, white birch $\left(\rho=740 \mathrm{~kg} / \mathrm{m}^{3}\right)$, aspens $\left(\rho=582 \mathrm{~kg} / \mathrm{m}^{3}\right)$, spruce $\left(\rho=469 \mathrm{~kg} / \mathrm{m}^{3}\right)$, white pine $\left(\rho=360 \mathrm{~kg} / \mathrm{m}^{3}\right)$, and Masters larch $\left(\rho=469 \mathrm{~kg} / \mathrm{m}^{3}\right)$ under external heat fluxes of 20 to $70 \mathrm{~kW} / \mathrm{m}^{2}$. The surface temperatures rose faster for larch than aspens, and faster for aspens than oak, as shown in Fig. 6. In their model, which correlates well with the experiments, thermal diffusivity was found to be the main factor contributing to differences between species.

Lizhong et al. [104] tested acacia, toon, and paulownia samples under linearly increasing heat fluxes, and found ignition temperatures for paulownia at $0.2986 \mathrm{~kW} / \mathrm{m}^{2} \mathrm{~s}$ to be $271^{\circ} \mathrm{C}$, toon $302^{\circ} \mathrm{C}$, and acacia $319^{\circ} \mathrm{C}$ - this shows only a small influence of species.

A number of furnace tests $[64,69,82,87,88]$ have explored the effects of species on charring rate. All authors observed a strong species dependence that cannot be attributed to other species-dependent properties such as density, but unlike previous variables, this can only be described qualitatively.

In White and Nordheim's tests [69], (discussed in Sect. 3.1.1) when a species-dependant factor was incorporated into Eq. (12) giving Eq. (18), the coefficient of determination increased from 0.755 to 0.906 .

$$
m=0.1526+0.000508 \rho+0.1475 f_{C}+Z_{1} w
$$


where $m$ is the "reciprocal char rate" $\left(\mathrm{s} / \mathrm{mm}^{1.23}\right)$. Species-dependent factors varied from 0.50 (Southern pine) to 2.05 (Engelmann spruce), thus there is considerable variation $(\sim 200 \%)$ across species, even once density, moisture content, permeability, and hardwood/softwood classification have been accounted for.

Schaffer's tests on Douglas fir, southern pine, and white oak [82] (discussed in Sect. 3.1.1) also resulted in an empirical model with species-dependent factors. These are given in Table 2 .

Again, it is clear that there is considerable variation between species after accounting for density and moisture content. The variability present in parameter $b$ may suggest that the relative effects of moisture content vary from one species to another, which may account for some of the variability between authors discussed in Sect. 3.1.2. Similarly, the variation in parameters $a$ and $b$ may suggest that the relative effects of density may vary from one species to another. Similarly, Mikkola [12] reports a $100 \%$ reduction in oxygen concentration caused a $50 \%$ decrease in charring rate for white pine [33], but only 35\% for Douglas fir [105].

Tran and White [64] recorded the lignin content of the samples they tested: redwood consisted of $37.1 \%$ lignin, southern pine $27.9 \%$, red oak $24.5 \%$, and basswood $19.8 \%$. It appears that increasing lignin content may produce an increased charring rate, however as mentioned previously, too many variables were present to allow this to be confirmed with confidence.

Yang et al. [87, 88] tested Taiwania, Japanese cedar, China fir, Douglas fir, and southern pine glulam samples to the standard temperature-time curve in a furnace. They found that charring rate and total heat released decreased from Taiwania, to Japanese cedar, to China fir, to Douglas fir, to southern pine, which does not correlate with density alone, suggesting an influence of species.

Hall [80] reviewed a number of papers giving burn-through times or charring rates for timber panels for various species. Bryan and Doman [106] found greenheart and teak to have burn-through times of $650 \mathrm{~s}$, iroko 450 to $500 \mathrm{~s}$, jarrah 400 to $450 \mathrm{~s}$, opepe and European oak 350 to $400 \mathrm{~s}$, and mahogany and spruce 250 to $300 \mathrm{~s}$. Whilst details of the test setup are not given, it can be seen that the variation between species can be over two times between the extreme cases of greenheart and teak compared to mahogany and spruce. Barnes [107] tested jarrah, teak, and European oak beams for burn-through time, finding jarrah had a time of $16.5 \mathrm{~min}$, teak $12.5 \mathrm{~min}$, and European oak 9.2 to $11.0 \mathrm{~min}$. Webster and Ashton [108] measured charring rates in a furnace for gurjun, spruce, teak, and European redwood. Average values for gurjun were $0.77 \mathrm{~mm} / \mathrm{min}$; for spruce $0.74 \mathrm{~mm} / \mathrm{min}$; for teak $0.62 \mathrm{~mm} / \mathrm{min}$; and for European redwood 0.81. For the common species,

\section{Table 2}

Species Constants for Eq. (14) (Data from [82], Units Adjusted)

\begin{tabular}{lccc}
\hline Species & $a$ & $b$ & $c$ \\
\hline Douglas fir & 0.00226 & 0.00455 & 0.330 \\
Southern pine & 0.00046 & 0.00095 & 1.013 \\
White oak & 0.00158 & 0.00317 & 0.592 \\
\hline
\end{tabular}


the results between these three tests do not correlate well. Hall's own tests [80] on 15 different species also found variation across species, but again did not correlate well with the results of [106-108].

Várhegyi et al. [109] reviewed previous tests on chestnut, and found significant differences between chestnut and other hardwoods and softwoods. Chestnut has a comparatively high char yield and undergoes significant pyrolysis at relatively low temperatures. These samples had a high inorganic extractive content, but acetone extraction was found to reduce the difference between species.

In 1953 the Timber Development Association published a document [17] which grouped 66 species of timber into six arbitrary categories with decreasing fire resistance. Some of these results are to be expected due to density, with balsa, a very light wood typically around $250 \mathrm{~kg} / \mathrm{m}^{3}$ density, on its own in Group 6, and Groups 1 and 2 consisting mostly of hardwoods. Groups 3-5 consist of various softwoods.

Whilst no quantitative conclusions can be drawn from the above collected test data, it can be noted that difference in species may have a marked effect on charring rate. Friquin [5] attributes this to lignin content, with higher lignin contents giving higher char yields. Collier [84] states that chemical composition influences charring rate due to its effects on kinetics and energetics of pyrolysis. It can also be noted that species can have a greater effect than density [15, 69, 82], as is evident from Eq. (18). For example, Hall [80] found teak $\left(\rho=630 \mathrm{~kg} / \mathrm{m}^{3}\right)$ to have a charring rate of $0.43 \mathrm{~mm} / \mathrm{min}$, whereas Iroko $\left(\rho=620 \mathrm{~kg} / \mathrm{m}^{3}\right)$ tested in the same conditions and with the same moisture content had a charring rate of $0.63 \mathrm{~mm} / \mathrm{min}$ - a much greater difference than one would expect to be accounted for by density alone.

\subsection{System Properties}

3.2.1. Sample Orientation As with any material, the pyrolysis rate of wood is affected by its orientation, due to its effects on fire dynamics and airflow. In vertical orientations, buoyancy will drive convection upwards parallel to the sample, resulting in very different conditions to horizontally orientated samples [71]. Charring rates are thus expected to be greater for vertically orientated samples due to increased radiation from the flame.

Shields et al. [40] directly explored the effects of sample orientation using a cone calorimeter. McAllister [42] performed further tests on poplar $\left(\rho=489 \mathrm{~kg} / \mathrm{m}^{3}\right)$ in the apparatus described in Sect. 3.1 .2 varying the airflow from $0.8 \mathrm{~m} / \mathrm{s}$ to $1.3 \mathrm{~m} / \mathrm{s}$. Whilst the sample orientation was not altered, the airflow will affect the fire dynamics in a similar manner, so this has been included for discussion in this section.

Shields et al. [40] tested $100 \mathrm{~mm} \times 100 \mathrm{~mm} \times 20 \mathrm{~mm}$ Sitka spruce samples under heat fluxes of 20 to $70 \mathrm{~kW} / \mathrm{m}^{2}$, and found that time to ignition is sufficiently shorter (and occurs at lower heat fluxes) for horizontal samples than for vertical samples. These distinctions are most noticeable at lower (20 to $40 \mathrm{~kW} / \mathrm{m}^{2}$ ) heat fluxes. For example, Sitka spruce at $50 \mathrm{~kW} / \mathrm{m}^{2}$ had piloted ignition times of $12 \pm 4 \mathrm{~s}$ in the horizontal configuration, and $20 \pm 5 \mathrm{~s}$ in the vertical configura- 
tion; and spontaneous ignition times of $27 \pm 11 \mathrm{~s}$ in the horizontal configuration and $50 \pm 10 \mathrm{~s}$ in the vertical configuration. Time to ignition is also greater for the underside of a sample than the topside. Spontaneous ignition times were found to be five to thirteen times greater for ceiling samples. No explanation for this is given.

McAllister [42] found that airflow velocity had only a weak influence on critical mass flux required for ignition in the range studied, with ignition delay increasing from $43 \mathrm{~s}$ at $0.8 \mathrm{~m} / \mathrm{s}$ to $53 \mathrm{~s}$ at $1.3 \mathrm{~m} / \mathrm{s}$ for $18 \%$ moisture content.

Lau et al. [67] and Yang et al. [87, 88] compared the charring rates over the sides and bottoms of beams tested in furnaces. With the exception of corner rounding, Lau et al. [67] found charring to be uniform over all sides. However Yang et al. [87, 88] found charring to be faster on the bottom face than the sides.

Ashton [46] reports that charring rate is $1.3 \times$ higher for columns than beams, suggesting that a vertical orientation results in faster pyrolysis.

The averages from all standard temperature-time curve tests reviewed herein give contradictory data; samples orientated horizontally give an average charring rate of $0.70 \mathrm{~mm} / \mathrm{min}$ with a standard deviation of $0.14 \mathrm{~mm} / \mathrm{min}$, and samples orientated vertically give an average charring rate of $0.63 \mathrm{~mm} / \mathrm{min}$ with a standard deviation of $0.11 \mathrm{~mm} / \mathrm{min}$. Due to this contradiction, the small number of authors investigating orientation, and the large standard deviations in the meta-analysis, no firm conclusions on the effects of sample orientation can be drawn.

3.2.2. Sample Size As well as the orientation of the sample, the size will also affect the pyrolysis behaviour. Increase in scale usually means lesser heat losses per unit volume of material, thus making samples easier to ignite [48].

Ritchie et al. [70] tested circular Douglas fir samples of diameters $100 \mathrm{~mm}$ and $600 \mathrm{~mm}$ in a cone calorimeter and large radiant panel facility respectively. Samples were exposed to an incident heat flux of $25 \mathrm{~kW} / \mathrm{m}^{2}$ after having been conditioned at $22^{\circ} \mathrm{C}$ and 50 to $55 \%$ relative humidity for a month, giving an equilibrium moisture content of 9.2 to $10.0 \%$ according to Eq. (16). The $100 \mathrm{~mm}$ samples showed initial heat release rate peaks of around 180 to $250 \mathrm{~kW} / \mathrm{m}^{2}$, whereas the $600 \mathrm{~mm}$ samples showed initial peaks of around 290 to $340 \mathrm{~kW} / \mathrm{m}^{2}$.

Hill and Comey [57] found that larger samples took much longer to ignite than smaller samples - small pieces around $0.5 \mathrm{~g}$ ignited in 15-20 min, whereas larger pieces around $15 \mathrm{~g}$ could take an hour or longer-and ignited at lower temperatures, decreasing from $204^{\circ} \mathrm{C}$ at $0.5 \mathrm{~g}$ to $181^{\circ} \mathrm{C}$ at $3 \mathrm{~g}$ to $175^{\circ} \mathrm{C}$ at $9 \mathrm{~g}$ to $158^{\circ} \mathrm{C}$ at $16 \mathrm{~g}$. This was attributed to greater heat losses through conduction and radiation.

There is generally good agreement that pyrolysis rate increases with sample size, although relatively few authors have directly investigated this effect. Figure 7 shows the charring rate plotted against sample size for standard temperature-time curve tests reviewed herein. It can be seen that for surface areas up to around $0.25 \mathrm{~m}^{2}$, there is a weak logarithmic increase in charring rate with surface area, however, above this value, the trend discontinues, perhaps in part due to larger surface areas not being completely exposed to the fire. Hadden et al. [110] found that the relative effects of sample size (for polyurethane foams) decrease with 


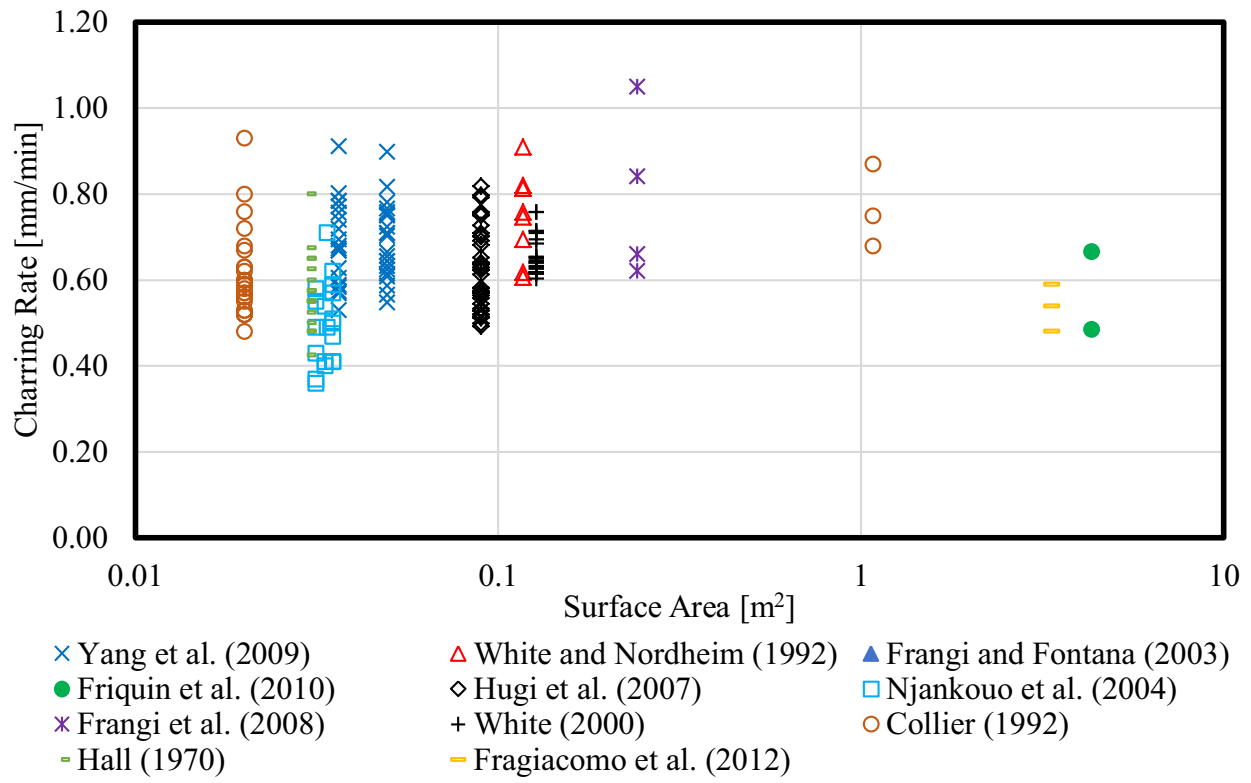

\section{Figure 7. Charring rate versus surface area plot for standard temperafure-time curve tests reviewed herein.}

increasing sample size, which is observed here through the logarithmic relationship.

Friquin [5] points out that the scale of the samples affects the heat and mass transfer, and thus the pyrolysis behaviour. She cites Suuberg et al. [111], who states that larger samples pyrolyse faster. Additionally, she cites Majamaa [112], who found that a $40 \mathrm{~mm}$ thick sample required $10 \mathrm{~min}$ to achieve a constant charring rate, and a $80 \mathrm{~mm}$ sample $30 \mathrm{~min}$, suggesting that sample thickness, as well as surface area, has an effect on pyrolysis behaviour. This can be attributed to the boundary condition at the back face - a thermally thin sample will achieve thermal penetration throughout the entire sample, resulting in an elevated back face temperature and heat losses from the rear of the sample. A thermally thick sample however, will not achieve an elevated back face temperature, and thus no heat will be lost via the rear of the sample.

3.2.3. Grain Direction The grain direction is also recognised as having an effect on pyrolysis behaviour [4, 5, 79, 84, 91, 113], largely due to the large increase (around 10,000 times) in permeability parallel to the grain [5, 84], due to the alignment of tracheids. As a result of this, small changes in grain angle can result in large changes in moisture and oxygen movement, thus affecting the charring rate [84]. Additionally, thermal conductivity is greater parallel to the grain than perpendicular to it [5]. As such, it is expected that charring rate will be greater parallel to the grain than perpendicular. 
White [83] tested various composite timber products to ASTM E 119 [95] in a vertical furnace, where he found that some tests showed slightly faster charring perpendicular to the grain than parallel, but this was attributed to delamination and fissures.

Buchanan and Barber [114] tested steel connections in timber members, and measured charring rates as $0.68 \mathrm{~mm} / \mathrm{min}$ parallel to laminations and $0.69 \mathrm{~mm} / \mathrm{min}$ perpendicular to the laminations.

Perhaps surprisingly, when comparing average charring rates between all the furnace tests reviewed herein which state the grain orientation, no significant difference was observed. It is also noteworthy that in design, timber elements will generally not have faces with parallel grains exposed, and thus only charring perpendicular to grain is likely to occur in practice.

\subsubsection{Encapsulation Schmid et al. [115] tested protected and unprotected CLT} beams in bending. They found that protective gypsum board delays the onset of charring and charring rate is slower than in an unprotected case, however charring rate increases significantly once the gypsum falls off, similar to the results of [116] and [117].

Hasburgh et al. [118] tested 12 CLT panels under a standard temperature-time curve with a variety of encapsulation systems. Two tests were undertaken with no encapsulation, four with one layer of gypsum plasterboard (two of which used a $19 \mathrm{~mm}$ "furring strip"), three with two layers of gypsum plasterboard (one with a $19 \mathrm{~mm}$ "furring strip"), one with three layers of gypsum plasterboard, and two with intumescent coatings. Encapsulation times were noted as $26.3-27.7 \mathrm{~min}$ for one layer of gypsum (increasing by $\sim 10 \%$ to $30.4-30.8$ min with a "furring strip"), 70.6-70.8 $\mathrm{min}$ for two layers (increasing by $\sim 10 \%$ to $78.6 \mathrm{~min}$ with a "furring strip"), and $130.4 \mathrm{~min}$ for three layers. Charring rates of the first lamella (calculated from the onset of charring) were found to vary from $0.80 \pm 0.04 \mathrm{~mm} /$ min for no encapsulation, $0.44 \pm 0.01 \mathrm{~mm} / \mathrm{min}$ for one layer of gypsum plasterboard $(0.54 \pm 0.02 \mathrm{~mm} / \mathrm{min}$ with a "furring strip"), $0.61 \pm 0.11 \mathrm{~mm} / \mathrm{min}$ with two layers of gypsum plasterboard, and $0.95 \mathrm{~mm} / \mathrm{min}$ with three layers. There is no clear pattern to this variation, however determining the total time taken to char through the first lamella (including the time taken for plasterboard falloff) shows a clear increase with number of layers of plasterboard, increasing from $44 \mathrm{~min}$ with no encapsulation, to $101 \mathrm{~min}$ with one layer, to $131 \mathrm{~min}$ with two layers, to $167 \mathrm{~min}$ with three layers (average times over multiple tests, including those with a furring strip).

Hakkarainen [117] tested four timber room structures of length $4.5 \mathrm{~m}$, width $3.5 \mathrm{~m}$, and height $2.5 \mathrm{~m}$ with a $2.3 \mathrm{~m} \times 1.2 \mathrm{~m}$ window. One compartment was unprotected, one was protected with one $12.5 \mathrm{~mm}$ layer regular gypsum plasterboard, and the other two were protected with $12.5 \mathrm{~mm}$ regular gypsum plasterboard and an additional $15.4 \mathrm{~mm}$ layer of gypsum plasterboard treated to improve core cohesion at elevated temperatures. Three of these tests were constructed of heavy laminated timber, and the other (two layers protection) of wood studs with mineral wool. Four wood cribs were used as a fuel load. Temperature was measured within the timber using K-type thermocouples at $0 \mathrm{~mm}, 6 \mathrm{~mm}$, 


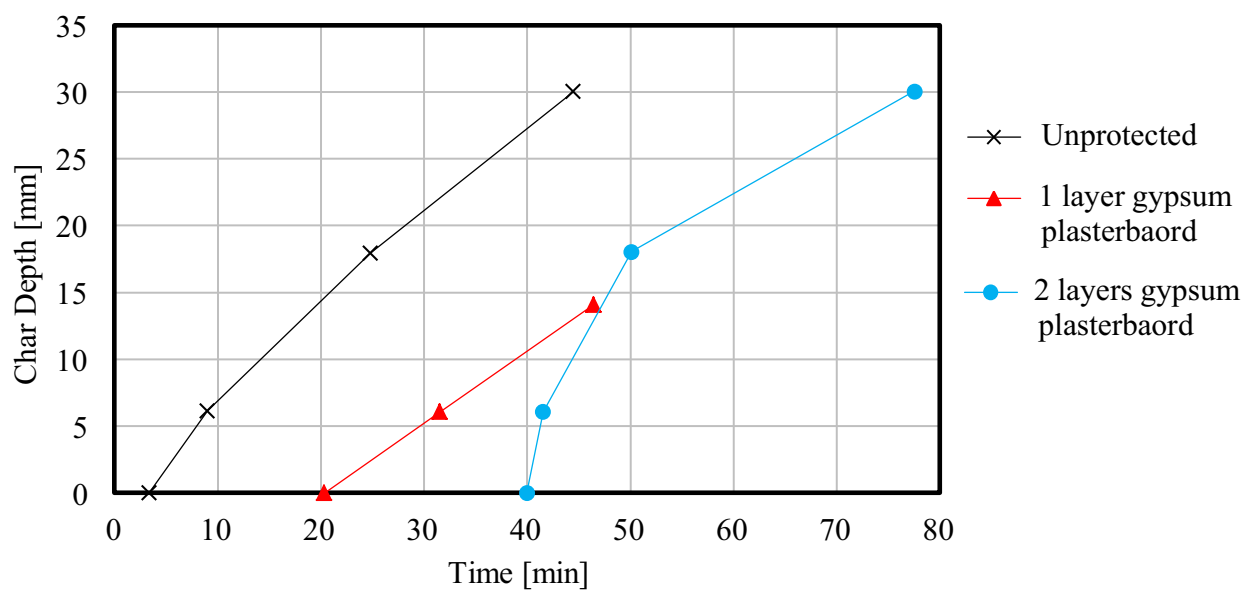

\section{Figure 8. Char depth versus time plot for unprotected and protected ceiling panels (data from [ 11 1 7 ).}

$18 \mathrm{~mm}, 30 \mathrm{~mm}, 42 \mathrm{~mm}$, and $54 \mathrm{~mm}$ below the exposed surfaces. Charring was assumed to occur at $300^{\circ} \mathrm{C}$. The evolution of charring depth with time for zero, one, and two layers gypsum protection is shown in Fig. 8. It can be seen that the presence of gypsum plasterboard delayed the onset of charring by around $20 \mathrm{~min}$ per layer. It was also observed that for the two-layer test, charring rate significantly increased once the protective layer dropped off, however this was not the case for the one-layer test. This was attributed to the long pre-heating time for the two-layer test.

It can be concluded that the presence of a protective layer of gypsum plasterboard reduces the charring rate of the underlying timber, but once said protection falls off, the charring rate is then significantly increased due to the lack of an insulating layer.

3.2.5. Delamination Delamination is a phenomenon through which the outer lamella (or part thereof) detaches from the second lamella, thus exposing unburned timber directly to the fire. The presence of a char layer also acts as protection for the underlying virgin wood $[4,5,13,15,27,39,69,70,81,82,84,85$, $89,93,116,119-122]$. As a result, the pyrolysis rate in a fire-exposed timber member is initially high whilst no protective layer exists, before decreasing to a lower quasi-constant value once a char layer has formed $[4-6,12,13,32,35,39,63,67$, $70,82,88,119,123,124]$. Schaffer suggests that a char depth of approximately $6.4 \mathrm{~mm}$ [82] or $12.7 \mathrm{~mm}$ [124] is required before the constant rate is reached, or that the time required to reach a steady state is given by Eq. 19, which is typically around $20 \mathrm{~min}$. This corresponds to a steady-state char layer, and thus steadystate heat transfer into the underlying timber. 


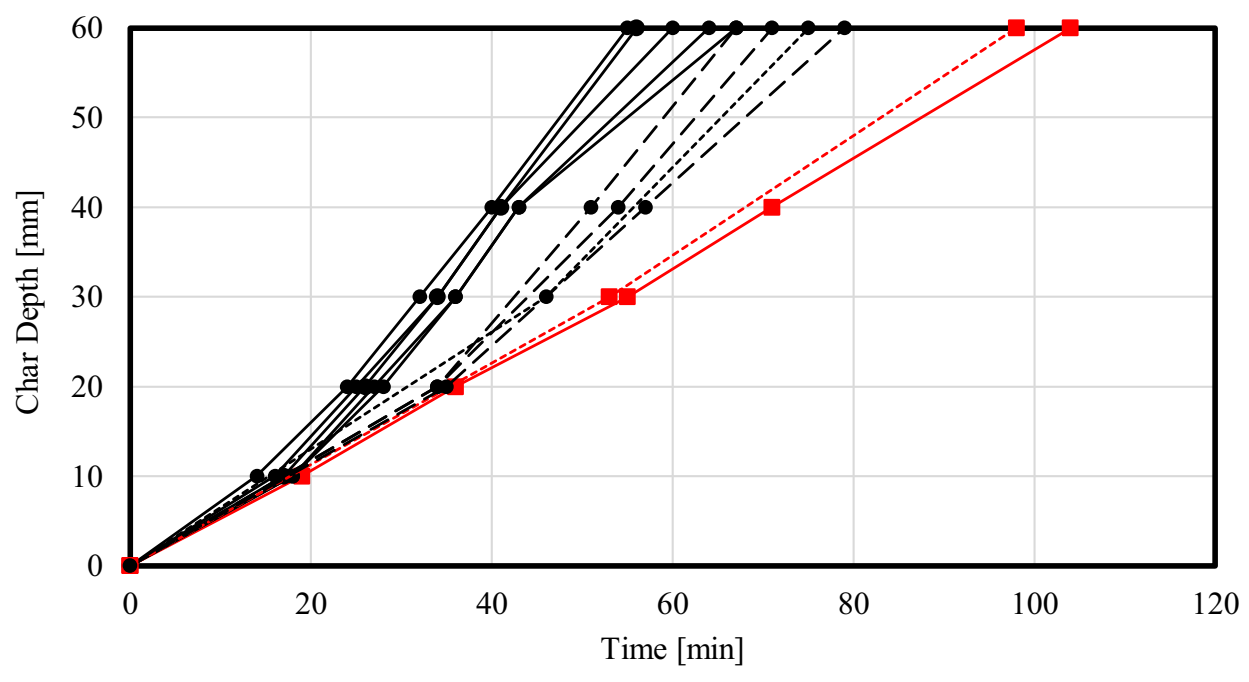

- MUF adhesive - PU adhesive -5 layers ---3 layers

2 layers

\section{Figure 9. Char depth as calculated by $300^{\circ} \mathrm{C}$ isotherm versus time plot for different adhesives and lamella build-ups (data from [ 116$]$ ).}

$$
t_{s s}=\frac{\alpha}{\beta_{s s}^{2}}
$$

where $\alpha$ is the thermal diffusivity $\left(\mathrm{m}^{2} / \mathrm{s}\right)$, and $\beta_{s s}$ is the steady-state charring rate $(\mathrm{m} / \mathrm{s})$. It is also commonly acknowledged that when protection falls off - either gypsum board or a lamella of an engineered timber product - the pyrolysis rate subsequently increases due to the absence of a protective char layer [115-117, 125]. The thickness of the lamellae is thus important to the fire behaviour - if the lamellae are sufficiently thick, then CLT will behave more like solid timber [119].

Frangi et al. [116] tested spruce CLT panels of dimensions $1.15 \mathrm{~m} \times 0.95 \mathrm{~m} \times$ $0.06 \mathrm{~m}$ with either two, three, or five layers. Nine specimens were bonded with a polyurethane (PU) adhesive, and two with a melamine urea formaldehyde (MUF) adhesive. Temperature was measured using K-type thermocouples at the gluelines. An additional $30 \mathrm{~mm}$ timber panel was placed on top of the samples, with an additional thermocouple in this boundary. The evolution of char depth with time is shown in Fig. 9 for all eleven tests. The lamella build-up was uniform for 2- and 3-layer tests, and four $10 \mathrm{~mm}$ layers and a $20 \mathrm{~mm}$ layer for the 5-layer tests. It can be seen that for samples bonded with PU adhesive, the charring rate increased after around $15 \mathrm{~min}$ - this is attributed to the layers falling off leaving an uncharred layer exposed - this was observed visually during the tests. For samples bonded with an MUF adhesive, the lamellae were not observed to fall off, and thus the charring rate remained approximately constant, behaving like a 
block of solid timber. Thicker lamellae generally showed lower overall charring rates due to delamination occurring less frequently.

Frangi et al. [119] then conducted an FE thermal analysis for CLT exposed to the standard temperature-time curve on specimens with either 3 lamellae of $9 \mathrm{~mm}$, or 3 lamellae of $18 \mathrm{~mm}$. It was assumed that the bonds between lamellae failed at $300^{\circ} \mathrm{C}$. Furnace tests were then carried out on $27 \mathrm{~mm}$ and $54 \mathrm{~mm}$ solid timber panels, and $3 \times 18 \mathrm{~mm}$ and two $3 \times 9 \mathrm{~mm}$ CLT panels made of spruce $\left(\rho=420 \mathrm{~kg} / \mathrm{m}^{2}\right)$ and moisture content $11 \%$, bonded with a PU adhesive - the $3 \times 9 \mathrm{~mm}$ panels were tested one on top of the other-essentially acting as a 6lamella sample without adhesive between the $3^{\text {rd }}$ and $4^{\text {th }}$ lamellae. The $54 \mathrm{~mm}$ thick specimens resulted in experimental charring rates of $0.66 \mathrm{~mm} / \mathrm{min}$ and $0.84 \mathrm{~mm} / \mathrm{min}$ for the solid timber and CLT panels respectively, and the $27 \mathrm{~mm}$ thick specimens $0.62 \mathrm{~mm} / \mathrm{min}$ and $1.05 \mathrm{~mm} / \mathrm{min}$ respectively. Average charring rates are not presented for the FE analysis, but are shown by plots of char depth against time. Taking the values at the failure times (38 min for the $54 \mathrm{~mm}$ CLT panel and $28 \mathrm{~min}$ for the $27 \mathrm{~mm}$ panels) gives average charring rates of $0.93 \mathrm{~mm} /$ min for the $54 \mathrm{~mm}$ panel and $1.18 \mathrm{~mm} / \mathrm{min}$ for the $27 \mathrm{~mm}$ panel-resulting in overpredictions of $10-12 \%$.

$\mathrm{Li}$ et al. carried out a full-scale compartment fire experiment in a $2.5 \mathrm{~m} \times 3.5 \mathrm{~m} \times 4.5 \mathrm{~m}$ room with fully exposed CLT surfaces formed of three uniform $35 \mathrm{~mm}$ lamellae. They measured an average charring rate of $0.85 \mathrm{~mm} /$ min in panels where they did not observe delamination, but $1 \mathrm{~mm} / \mathrm{min}$ in the ceiling where delamination was observed.

Hadden et al. [126] also carried out a series of compartment fire experiments in a $2.7 \mathrm{~m} \times 2.7 \mathrm{~m} \times 2.7 \mathrm{~m}$ room, with partially exposed CLT surfaces. They observed sharp increases in burning rate coinciding with the onset of significant delamination.

Friquin [5] relates the protective quality of the char layer to several factors. The char layer will be thinner than the virgin wood, due to a combination of char oxidation, mechanical surface degradation, and char contraction. The char conversion is the fraction of wood that is converted to char. With increasing char conversion, charring rate decreases due to an increased protective layer. White et al. [64, 69, 81] included a char conversion factor in their models (see Sect. 3.1.1), accounted for through Eq. (13); Eq. (12) shows charring rate to decrease as char conversion factor increases.

It is clear from the available research that delamination will cause an increase in the charring rate until a protective char layer is built up again. Whilst the effects of delamination are understood, its causes remain unpredictable. In particular, the failure modes and conditions of different adhesives used in manufacture of engineered timber products are not well understood.

\subsection{Thermal Exposure}

3.3.1. Heating Scenario The heating scenario (conventionally this is defined as either a temperature-time curve or an incident heat flux) is known to affect the pyrolysis rate $[11,12,16,20,21,32,71,82,88,91,93,97,98,103,121,127-129]$. 
Some of the earliest work on the ignition properties of wood is by Hill and Comey [57] from 1886, in which they tested pine samples in a metal heating bath, equivalent to a modern oven with different heating rates, with temperatures recorded by mercurial and air thermometers. It was found that if the sample was heated slowly, it had charred before ignition could occur, and thus it was char, not wood igniting, at temperatures around 405 to $417^{\circ} \mathrm{C}$, but if heated quickly, would ignite at lower temperatures, around 360 to $372^{\circ} \mathrm{C}$.

Hill and Comey [130] then tested small wood samples in constant gas temperatures, and measured the direct and indirect carbon dioxide production. They found carbon dioxide production per gram per hour to increase exponentially from $0.09 \mathrm{mg} / \mathrm{gh}$ at $123^{\circ} \mathrm{C}$ to $6.67 \mathrm{mg} / \mathrm{g}$ at $220^{\circ} \mathrm{C}$.

The majority of research exploring the effect of heating scenario on charring rate has been undertaken under radiant heating $[7,12,32,71,81,85,88,98,103$, 104, 129]. The majority of researchers observed a clear increase in charring rate with increasing heat flux.

Mikkola [12] (see Sect. 3.1.2), investigated the effect of incident radiant heat flux, and applied a simple energy balance to determine the relationship between heat flux and charring rate, shown in Eq. (20):

$$
\dot{q}_{n}^{\prime \prime}=\dot{m}^{\prime \prime}\left[C_{p}\left(T_{p}-T_{\infty}\right)+L_{v}\right]
$$

where $\dot{q}_{n}^{\prime \prime}$ is the net heat flux, $C_{p}$ is the specific heat capacity, and $L_{v}$ is the heat of gasification of wood. Combining this with Eq. (10) yields Eq. (21):

$$
\beta=\frac{\dot{q}_{n}^{\prime \prime}}{\rho\left[C_{p}\left(T_{p}-T_{\infty}\right)+L_{v}\right]}
$$

Application of Eq. (21) gave charring rates of $0.81 \mathrm{~mm} / \mathrm{min}$ for spruce and $0.70 \mathrm{~mm} / \mathrm{min}$ for pine, whereas experimental values obtained were $0.80 \mathrm{~mm} / \mathrm{min}$ for both. As can be seen, charring rate is linearly dependent on net heat flux.

Di Blasi et al. [103] tested cylindrical beech $\left(\rho=730 \mathrm{~kg} / \mathrm{m}^{3}\right)$, chestnut $\left(\rho=590 \mathrm{~kg} / \mathrm{m}^{3}\right)$, Douglas fir $\left(\rho=515 \mathrm{~kg} / \mathrm{m}^{3}\right)$, redwood $\left(\rho=488 \mathrm{~kg} / \mathrm{m}^{3}\right)$, and pine $\left(\rho=450 \mathrm{~kg} / \mathrm{m}^{3}\right)$ samples of height and diameter $40 \mathrm{~mm}$ to radiant heat fluxes of $28 \mathrm{~kW} / \mathrm{m}^{2}$ to $80 \mathrm{~kW} / \mathrm{m}^{2}$. The heat flux was applied in the radial direction. Steady centreline temperature increased from $327^{\circ} \mathrm{C}$ to $677^{\circ} \mathrm{C}$ over the range of heat fluxes tested.

Yang et al. [88] tested China fir, Japanese cedar, and Taiwania samples in the cone calorimeter to a constant $50 \mathrm{~kW} / \mathrm{m}^{2}$ for $15 \mathrm{~min}$, and $40 \mathrm{~kW} / \mathrm{m}^{2}$ for $5 \mathrm{~min}$. The peak heat release rates were $14 \%, 27 \%$, and $13 \%$ greater for $50 \mathrm{~kW} / \mathrm{m}^{2}$ than $40 \mathrm{~kW} / \mathrm{m}^{2}$ for Japanese cedar, Taiwania, and China fir respectively.

Lizhong et al. [104] found that surface temperatures under linearly increasing heat fluxes continue to rise steadily, whereas constant heat fluxes rise rapidly, before then continuing to rise much slower. For constant heat fluxes, time to ignition is proportional to the inverse of the heat flux squared, as in Eq. (3), but for linearly increasing heat fluxes, $t_{i g} \propto \gamma^{-0.6897}$, where $\gamma$ is the rate of increase of heat 
flux, suggesting significant differences in behaviour between different shapes of heating curve.

White and Tran [81] tested redwood $\left(\rho=309 \mathrm{~kg} / \mathrm{m}^{3}\right)$, pine $\left(\rho=450 \mathrm{~kg} / \mathrm{m}^{3}\right)$, red oak $\left(\rho=682 \mathrm{~kg} / \mathrm{m}^{3}\right)$, and basswood $\left(\rho=408 \mathrm{~kg} / \mathrm{m}^{3}\right)$ under constant radiative heat fluxes of $15,25,35$, and $50 \mathrm{~kW} / \mathrm{m}^{2}$. The specimens tested were $64 \mathrm{~mm}$ thick, and had a surface area of $150 \mathrm{~mm} \times 150 \mathrm{~mm}$, formed of four lamellae. Specimens were tested vertically, heated by silicon carbide heater element, with a pilot flame above the sample. Temperature was measured with K-type thermocouples at $6 \mathrm{~mm}, 12 \mathrm{~mm}, 18 \mathrm{~mm}, 24 \mathrm{~mm}$, and $36 \mathrm{~mm}$ from the surface. Charring was assumed to occur at $300^{\circ} \mathrm{C}$. Using the model $t=m x_{c}^{a}$ developed in [69], $a$ was found to increase with incident heat flux, suggesting increasing non-linearity with higher incident heat fluxes.

Considering charring rate, the expression in Eq. (22) was developed:

$$
\beta=0.0121 \dot{q}^{\prime \prime}-0.00139 \rho-0.0199 l+1.527
$$

where $l$ is the lignin content. This shows a linear dependence of charring rate on incident heat flux.

Reszka and Torero [98, 129] tested $100 \mathrm{~mm} \times 97 \mathrm{~mm} \times 67 \mathrm{~mm}$ redwood pine $\left(\rho=545 \mathrm{~kg} / \mathrm{m}^{3}\right)$ samples vertically in the cone calorimeter at heat fluxes between 10 and $60 \mathrm{~kW} / \mathrm{m}^{2}$ perpendicular to the grain. Temperature was measured by $\mathrm{K}$ type thermocouples inserted through the back face at depths every $5 \mathrm{~mm}$ up to $40 \mathrm{~mm}$. An aluminium block was placed at the back to provide a well-defined end boundary condition. Increased heat fluxes were found to provide more rapid indepth heating and mass loss rates than lower heat fluxes. Repeatability was good for the $60 \mathrm{~kW} / \mathrm{m}^{2}$ tests, but poorer for the $10 \mathrm{~kW} / \mathrm{m}^{2}$ tests. Two types of result were observed; one which underwent thermal runaway at $200^{\circ} \mathrm{C}$, and one which showed long plateaus, taking many hours to reach thermal runaway. The theoretical temperature profile below the char line can be given by Eq. (23):

$$
T(x)=T_{\infty}+\left(300-T_{\infty}\right)\left(1-\frac{x}{40}\right)^{2}
$$

where $x$ is the distance below the char line.

Butler [71] compared Baltic redwood tested in furnaces for long durations at heat fluxes between $5 \mathrm{~kW} / \mathrm{m}^{2}$ and $60 \mathrm{~kW} / \mathrm{m}^{2}$ (shown in Fig. 10), and Guatemala cedar tested in a carbon arc for short durations at heat fluxes of 300 to $3300 \mathrm{~kW} /$ $\mathrm{m}^{2}$. This gives the relationship in Eq. (24):

$$
\beta=0.02202 \dot{q}^{\prime \prime}
$$

This can be compared with the same plot for constant heat flux tests reviewed herein, shown in Fig. 10. Whilst the range is much smaller, and the scatter thus more visible (largely due to variation in the other parameters discussed previously), when a line of best fit through the origin is plotted, it yields Eq. (25): 


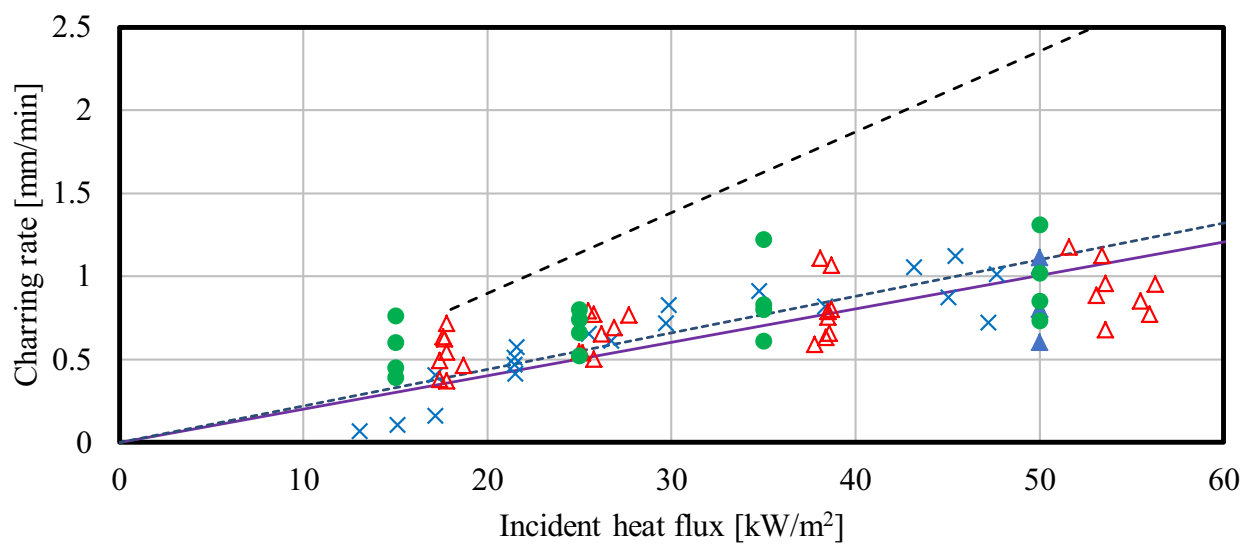

$\times \quad$ Butler [90]

$\Delta \quad$ Mikkola [23]

- - - White and Deitenberger [30]

----- Fit from Butler [90]
$\Delta \quad$ Tran and White [148]

- White and Tran [108]

- Fit from reviewed data

\section{Figure 10. Charring rate versus incident heat flux plot for constant heat flux tests reviewed herein.}

$$
\beta=0.02014 \dot{q}^{\prime \prime}
$$

which is very similar to Eq. (24), thus suggesting that charring rate does have a strong linear dependence on incident heat flux. However it should be noted that since the higher heat fluxes were tested for only short durations, it is likely that only the initial charring peak was captured, and not the subsequent quasi-constant charring rate, giving artificially high readings in Fig. 10. Lie [91] also states that charring rate is a linear function of heat flux. Furthermore, White and Dietenberger [20] state that charring rate varies from $0.8 \mathrm{~mm} / \mathrm{min}$ to $2.6 \mathrm{~mm} / \mathrm{min}$ for external heat fluxes of 18 to $55 \mathrm{~kW} / \mathrm{m}^{2}$, giving a slope twice as steep as than in Eqs. (24) and (25), shown in Fig. 10.

Lizhong et al. [104] tested acacia, elm, toon, and paulownia under linearly increasing heat fluxes of $0.20 \mathrm{~kW} / \mathrm{m}^{2} \mathrm{~s}, 0.30 \mathrm{~kW} / \mathrm{m}^{2} \mathrm{~s}, 0.42 \mathrm{~kW} / \mathrm{m}^{2} \mathrm{~s}$, and $0.57 \mathrm{~kW} / \mathrm{m}^{2} \mathrm{~s}$. They found that there was a consistent increase in ignition temperature for all species from $0.30 \mathrm{~kW} / \mathrm{m}^{2} \mathrm{~s}$ to $0.42 \mathrm{~kW} / \mathrm{m}^{2} \mathrm{~s}$ of around 20 to $30^{\circ} \mathrm{C}$, but there was no significant difference in ignition temperature between the heating rates of $0.42 \mathrm{~kW} / \mathrm{m}^{2} \mathrm{~s}$ and $0.57 \mathrm{~kW} / \mathrm{m}^{2} \mathrm{~s}$, summarised in Fig. 11. They observed that smouldering ignition occurred prior to a transition to flaming. Mass loss rates at time of ignition did not directly correspond to heating rates, but were generally in the range of 20 to $30 \mathrm{~g} / \mathrm{m}^{2} \mathrm{~s}$.

Lizhong et al. [85] tested $100 \mathrm{~mm} \times 100 \mathrm{~mm} \times 20 \mathrm{~mm}$ samples of paulownia $\left(\rho=260 \mathrm{~kg} / \mathrm{m}^{3}\right)$, toon $\left(\rho=530 \mathrm{~kg} / \mathrm{m}^{3}\right)$, and elm $\left(\rho=590 \mathrm{~kg} / \mathrm{m}^{3}\right)$ in a radiation platform to linearly increasing heat fluxes, ranging from $0.07 \mathrm{~kW} / \mathrm{m}^{2} \mathrm{~s} 0.425 \mathrm{~kW} / \mathrm{m}^{2} \mathrm{~s}$. Temperature was measured using type-K thermocouples at $0 \mathrm{~mm}, 2 \mathrm{~mm}, 6 \mathrm{~mm}$, 


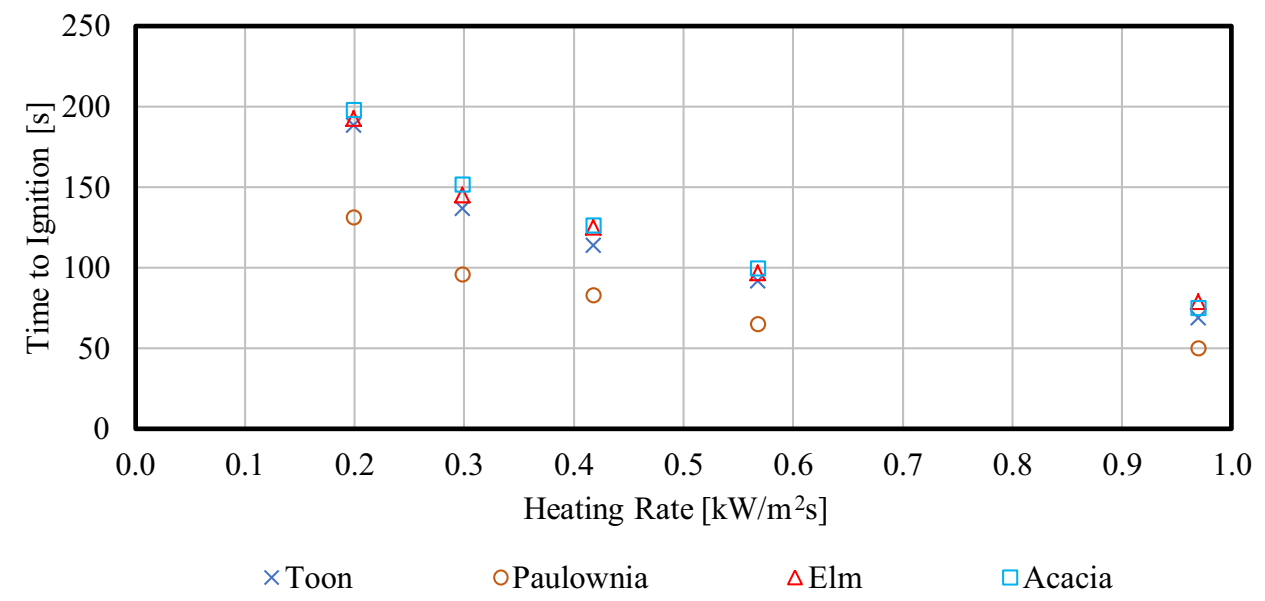

\section{Figure 11. Time to ignition for four wood species as a function of heating rate (data from [ 104$]$ ).}

and $10 \mathrm{~mm}$ below the exposed surface. Charring was assumed to occur at $300^{\circ} \mathrm{C}$. The charring rate increased with heating rate from $0.31 \mathrm{~mm} / \mathrm{min}$ to $0.95 \mathrm{~mm} / \mathrm{min}$, giving the empirical relationship in Eq. (26):

$$
\beta=136 \gamma^{0.51} \rho^{-0.76}
$$

where $\gamma$ is the rate of increase of heat flux.

Kashiwagi et al. [32] tested $38 \mathrm{~mm}$ cubes of white pine $\left(\rho=380 \mathrm{~kg} / \mathrm{m}^{3}\right)$ in a radiant heating apparatus consisting of a $100 \mathrm{~mm} \times 130 \mathrm{~mm}$ graphite plate heated to $1250^{\circ} \mathrm{C}$ with a $90 \mathrm{~mm} \times 90 \mathrm{~mm}$ water-cooled pipe transmitting spatially uniform radiation to the sample at heat fluxes of $25 \mathrm{~kW} / \mathrm{m}^{2}, 40 \mathrm{~kW} / \mathrm{m}^{2}$, and $69 \mathrm{~kW} / \mathrm{m}^{2}$. Increased heat flux was found to produce a sharper, earlier peak in pyrolysis rate. Quasi-steady surface temperature increased from $500^{\circ} \mathrm{C}$ at $25 \mathrm{~kW} / \mathrm{m}^{2}$ to $700^{\circ} \mathrm{C}$ at $69 \mathrm{~kW} / \mathrm{m}^{2}$. They found that the thermal wave penetrated much further at higher heat fluxes due to a steeper thermal gradient, tending to increase the char depth. Carbon monoxide, carbon dioxide, and hydrocarbon generation was seen to increase with heat flux.

Moghtaderi et al. [39] found that ignition temperature decreased with external heat flux, from $366^{\circ} \mathrm{C}$ at $20 \mathrm{~kW} / \mathrm{m}^{2}$ to $335^{\circ} \mathrm{C}$ at $60 \mathrm{~kW} / \mathrm{m}^{2}$ at $15 \%$ moisture content, due to shorter ignition times.

Furthermore, Inghelbrecht [7] found that the mass loss rate (and thus charring rate) tended towards an asymptotic value regardless of heat flux, suggesting that it is only the initial, high charring rate, which can be 4-5 times the steady-state charring rate, (see Sect. 3.2.4) that is dependent on external heat flux. Charring rate under steady-state conditions has minimal dependence on external heat flux.

Schaffer [82] tested Douglas fir, southern pine, and white oak in a furnace at constant exposure temperatures of $538^{\circ} \mathrm{C}, 816^{\circ} \mathrm{C}, 927^{\circ} \mathrm{C}$. It was observed that 
higher temperatures yielded higher charring rates. Additionally, it was found that char formed at gas temperatures of $538^{\circ} \mathrm{C}$ had a finer texture than that formed above $538^{\circ} \mathrm{C}$. It was found for the higher exposure temperatures that two structurally distinct char layers had formed of approximately equal thickness, with the inner layer having greater structural strength. These differences are not defined by the author, and are likely to be a gradient of strength as a function of how complete the pyrolysis is.

Silcock and Shields [128] compared char depth to local fire severity, which they defined in Eq. (27).

$$
L F S=\int_{0}^{\tau} \dot{q}(t)^{\prime \prime} d t
$$

where $\tau$ is the total fire duration, and $\dot{q}(t)^{\prime \prime}$ is the incident heat flux. Comparing cone calorimeter and furnace tests with this definition, they found the expression in Eq. (28).

$$
x_{c}=0.675 L F S^{0.645}
$$

Where $x_{c}$ is char depth, again showing char depth to increase with incident heat flux.

There is good agreement between authors that charring rate increases with increasing heat flux. From the works available, this is an approximately linear function. Because exposures are not consistent between works, it is hard to draw definite conclusions. It is also noteworthy that only Inghelbrecht [7] explores the effect of the initial peak, and observes a much weaker dependence thereafter. This is particularly important to consider for longer (or shorter) fire durations.

\subsection{Oxygen Concentration}

The oxygen concentration in the environment surrounding the exposed timber also influences its pyrolysis and combustion behaviour - a lower oxygen concentration will result in lower char oxidation rates, thus there will be more char to reduce the heat transfer into the underlying timber. This has been found to result in a decreased charring rate with decreasing oxygen concentration $[12,32,84,94$, 97], with the exception of Butler [71] found that tests in nitrogen and air showed little difference in charring rate, however this is likely due to the large range of heat fluxes tested, which would dominate over variations in oxygen concentration.

Several researchers [12, 32, 33, 72, 97] explored the effects of oxygen concentration on timber pyrolysis under radiative heating, finding that charring rate decreased with decreasing oxygen concentration.

Mikkola [12] found that mass loss rates decrease by approximately $20 \%$ for a $50 \%$ reduction in oxygen concentration, and 50\% with $100 \%$ for white pine [33], and $35 \%$ for a $100 \%$ reduction for Douglas fir [105]. 
Babrauskas [97] found that in furnace tests, typical oxygen concentration varies from $4 \%$ to $10 \%$. At around $8 \%$ to $10 \% \mathrm{O}_{2}$, charring rate decreases by around $20 \%$ from ambient conditions, and a further $33 \%$ at $4 \% \mathrm{O}_{2}$ (to just over $50 \%$ of charring rate at ambient conditions).

Kashiwagi et al. [32] varied oxygen concentration from $0 \%$ to $10.5 \%$ to $21 \%$. Mass flux was found to increase with increased oxygen concentration. After $3 \mathrm{~min}$ exposure to $25 \mathrm{~kW} / \mathrm{m}^{2}$, the mass flux in air was approximately four times that in nitrogen.

Delichatsios [72] exposed $100 \mathrm{~mm} \times 100 \mathrm{~mm} \times 4 \mathrm{~mm}$ regular and fire retarded plywood to 25,35 and $50 \mathrm{~kW} / \mathrm{m}^{2}$ heat fluxes in a cone calorimeter at oxygen concentrations of 21,18 , and $15 \%$. The samples were insulated at the back face by $46 \mathrm{~mm}$ ceramic board. The fire retarded plywood was found to have ignition times increasing very slightly with decreasing oxygen concentration, from $54 \mathrm{~s}$ at $21 \%, 57 \mathrm{~s}$ at $18 \%$, and $59 \mathrm{~s}$ at $15 \%$ under $35 \mathrm{~kW} / \mathrm{m}^{2}$, and decreasing with increasing heat flux. The regular plywood samples also showed very little dependence on oxygen concentration.

Ohlemiller et al. [33] tested $38 \mathrm{~mm} \times 38 \mathrm{~mm}$ white pine and red oak samples in a radiative heating apparatus at oxygen concentrations of $0 \%, 10.5 \%$, and ambient, parallel to the grain. They found that at $40 \mathrm{~kW} / \mathrm{m}^{2}$, mass flux was about twice that in nitrogen; at $25 \mathrm{~kW} / \mathrm{m}^{2}$ it was approximately four times. Different oxygen concentrations start having effects on pyrolysis at surface temperatures around $350^{\circ} \mathrm{C}$. Char forms more rapidly in an oxygen-rich environment, which speeds up local temperature rise and pyrolysis reactions. Between 120 and $240 \mathrm{~s}$, the front surface achieved a quasi-steady value of $650^{\circ} \mathrm{C}$ in air, and $550^{\circ} \mathrm{C}$ in nitrogen. Furthermore, the pyrolysis zone thickness was found to be just $10 \mathrm{~mm}$ in nitrogen, but $15 \mathrm{~mm}$ in air. The exothermic char oxidation process adds to the external heat flux, increasing pyrolysis rates. Thermogravimetric analyses at $5^{\circ} \mathrm{C} /$ min found char to oxidise at 400 to $500^{\circ} \mathrm{C}$, but at temperatures in excess of $650^{\circ} \mathrm{C}$ at $40 \mathrm{~kW} / \mathrm{m}^{2}$. In nitrogen, the initial product released is water, followed at surface temperatures around 300 to $400^{\circ} \mathrm{C}$ by tars which then dilute the water. Carbon monoxide, carbon dioxide and hydrocarbons follow more slowly at the same temperatures. As tars pass through the char layer, they may undergo cracking to smaller hydrocarbons, or polymerisation to a char. Since the hydrocarbon yield does not increase as rapidly as tar production falls, this suggests some tars do repolymerise to char, possibly forming water in the process. The yield of carbon monoxide and carbon dioxide increases dramatically in oxygen, due to the greater availability of oxygen to form these compounds through char oxidation. Greater heat fluxes led to earlier and higher mass loss peaks. Quasi-steady surface temperature also increases with heat flux, from $550^{\circ} \mathrm{C}$ at $25 \mathrm{~kW} / \mathrm{m}^{2}$, to $650^{\circ} \mathrm{C}$ at $40 \mathrm{~kW} / \mathrm{m}^{2}$, to $750^{\circ} \mathrm{C}$ at $69 \mathrm{~kW} / \mathrm{m}^{2}$.

In Cedering's [94] tests on timber stud walls (see Sect. 3.1.2), oxygen concentration was set at 4,7 , and $10 \%$. It was found that the charring rate increased with oxygen content - with averages of $0.65 \mathrm{~mm} / \mathrm{min}$ at $4 \%, 0.68 \mathrm{~mm} / \mathrm{min}$ at $7 \%$, and $0.70 \mathrm{~mm} / \mathrm{min}$ at $10 \%$. This was shown to be less important at higher moisture contents. 


\subsection{Overall Summary}

The effects of various parameters on the pyrolysis rates of wood have been extensively, if not systematically, studied. This is most easily quantified through "charring rate". A summary of these parameters and their relative importance is given in Table 3. In the works discussed above, several different criteria have been used to determine charring rates, however this is not critical due to sharp mass loss peaks occurring at well-defined temperatures. Various different temperatures have been used to determine the location of the char front; this is commonly defined as $288^{\circ} \mathrm{C}$ in North America and $300^{\circ} \mathrm{C}$ elsewhere, but has been found to be as high as $360^{\circ} \mathrm{C}$ in some cases. The precise temperature is not critical due to the steep temperature gradient at the charring front [5].

Whilst there is considerable scatter in the results presented in this paper, it can be clearly seen that the effect of incident heat flux is the most dominant parameter, with an order of magnitude higher influence than the other parameters considered, over the ranges to be expected in normal design. Therefore, it is vital that this influence be properly understood to allow safe, robust structural fire engineering design. It is therefore also crucial to develop a proper, scientific understanding of the fire exposures that are likely to manifest in timber compartments, particularly those with a significant amount of exposed structural timber.

\section{Conclusions}

This paper has presented a review of the pyrolysis, ignition, and combustion processes associated with timber products, and reviewed the factors that influence these processes.

The pyrolysis and burning behaviour of timber is well understood, with significant data available under a range of experimental conditions. There is generally good agreement between studies. It is evident that little of this research is carried through to design, with fixed charring rates forming the basis of most design codes. Whilst a simplistic approach may be sufficient for a long duration where complex system effects do not occur, this approach fails to capture the necessary physics related to the stochastic processes which may occur in a real fire.

The burning of timber was shown to depend on material, system, and fire properties. The effects of material properties are well understood from the fire science literature, and fire resistance tests have shown that for the ranges expected in design, only a small change (conservatively estimated at $18 \%$ ) in charring rate would be expected.

System properties are shown to be more significant. Delamination and encapsulation failure are critical to predicting the fire performance of timber, however very little research is available on these phenomena. These processes cannot be adequately captured in small-scale experiments, but have been observed in numerous furnace tests and compartment fire experiments. Whilst these experiments allow observation of the phenomena, and quantification of their effects, no understanding of the underlying causes and potential mitigation methods are available. These phenomena appear to be stochastic and complex. 


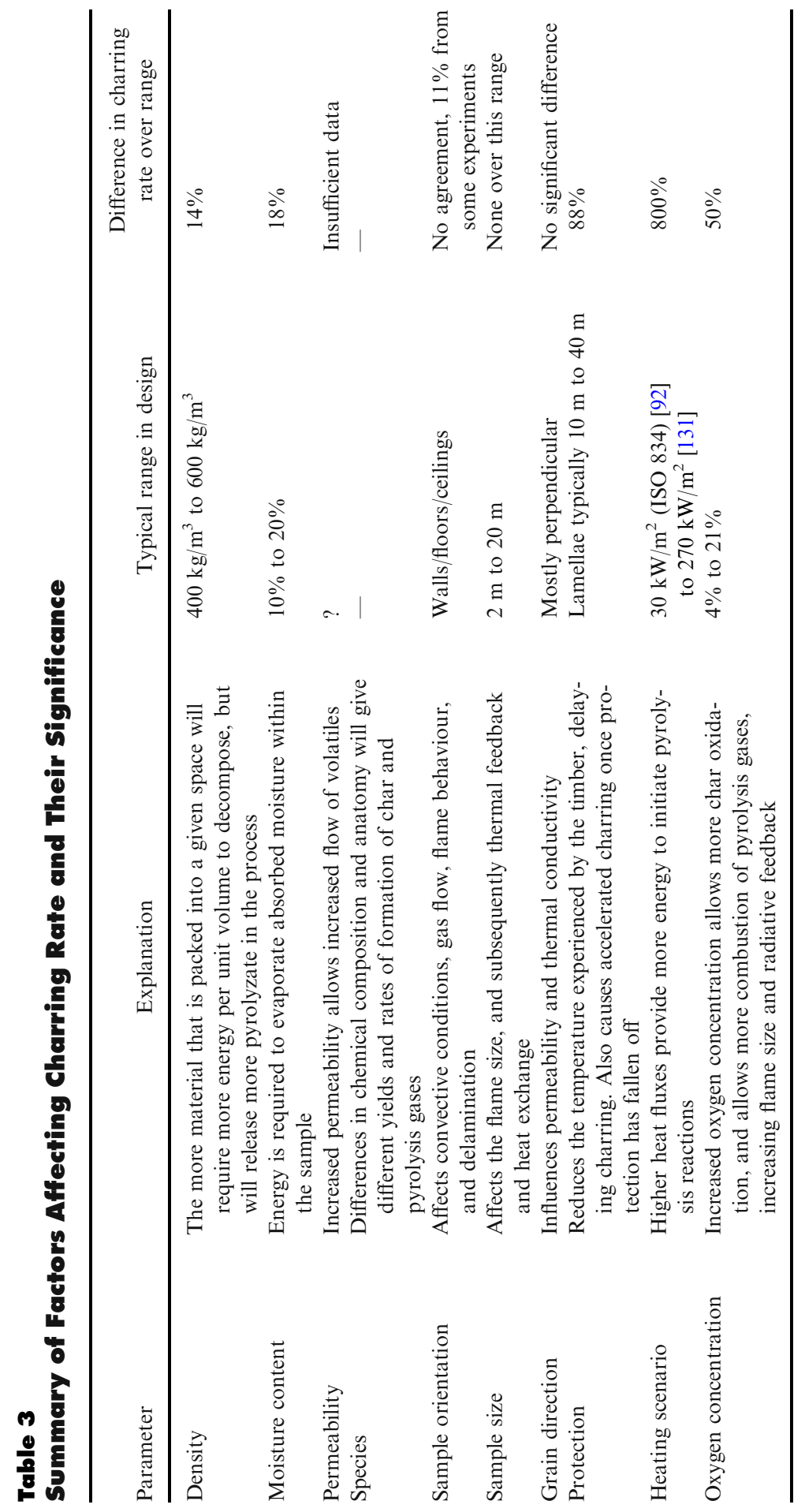


The fire scenario, which must be quantified by the incident heat flux, has been shown to have by far the largest effect on charring rate, and the resulting in-depth temperature evolution. This is key in understanding the mechanical response of timber upon fire exposure. It is clear from the fire science literature that the incident heat flux controls the material response-from the ignition and burning behaviour, through to flaming extinction. This represents two aspects that must be considered in design - the ignition and burning behaviour are required to characterise the risk, and understanding the auto-extinction behaviour is necessary to demonstrate compliance with the intent of many existing building regulations.

The challenges associated with tall, complex timber buildings will only be overcome once the fundamental knowledge available on the material behaviour can successfully be applied under realistic conditions. This is a fundamental challenge across all of fire engineering, however the specific risks posed by timber structures necessitate a common dialogue between fire scientists and engineers, and structural engineers to undertake design of such buildings in a rational manner.

\section{Acknowledgement}

The authors gratefully acknowledge generous support from Arup, partly through EPSRC iCASE Studentship 14220013.

\section{Open Access}

This article is distributed under the terms of the Creative Commons Attribution 4.0 International License (http://creativecommons.org/licenses/by/4.0/), which permits unrestricted use, distribution, and reproduction in any medium, provided you give appropriate credit to the original author(s) and the source, provide a link to the Creative Commons license, and indicate if changes were made.

\section{References}

1. CEN (2004) Eurocode 5. Design of timber structures. Part 1-2: general. Structural fire design. European Committee for Standardisation, Brussels

2. Law A, Bartlett A, Hadden R, Butterworth N (2014) The challenges and opportunities for fire safety in tall timber construction. Paper presented at the second international tall building fire safety conference, Greenwich, London

3. Hirschler MM, Morgan AB (2008) Thermal decomposition of polymers. In: SFPE handbook of fire protection engineering, vol 3, pp 1-112-111-143

4. Drysdale D (2011) An introduction to fire dynamics. Wiley, Hoboken

5. Friquin KL (2011) Material properties and external factors influencing the charring rate of solid wood and glue-laminated timber. Fire Mater 35(5):303-327

6. Yang L, Chen X, Zhou X, Fan W (2003) The pyrolysis and ignition of charring materials under an external heat flux. Combust Flame 133(4):407-413 
7. Inghelbrecht A (2014) Evaluation of the burning behaviour of wood products in the context of structural fire design. MSc, The University of Queensland, Ghent University

8. Matson AF, DuFour RE, Breen JF (1959) Survey of available information on ignition of wood exposed to moderately elevated temperatures, Part II of performance of type B gas Vents for gas-fired appliances (Bull. of Research 51). Underwriters' Laboratories, Inc., Chicago

9. Forest Products Laboratory (1958) Report 2136. United States Department of Agriculture, Forest Service, Madison, WI. https://ir.library.oregonstate.edu/downloads/3r0 $74 \mathrm{z} 89 \mathrm{~g}$

10. Di Blasi C (2008) Modeling chemical and physical processes of wood and biomass pyrolysis. Prog Energy Combust Sci 34(1):47-90. https://doi.org/10.1016/ j.pecs.2006.12.001

11. Roberts A (1971) Problems associated with the theoretical analysis of the burning of wood. In: Symposium (international) on combustion, vol 13. Elsevier, London, pp 893-903

12. Mikkola E (1991) Charring of wood based materials. In: Fire safety science-proceedings of the third international symposium. Elsevier Applied Science, London, pp 547556

13. Buchanan AH (2001) Structural design for fire safety. Wiley, New York

14. Grønli MG, Melaaen MC (2000) Mathematical model for wood pyrolysis comparison of experimental measurements with model predictions. Energy Fuels 14(4):791-800

15. Schmid J, Just A, Klippel M, Fragiacomo M (2014) The reduced cross-section method for evaluation of the fire resistance of timber members: discussion and determination of the zero-strength layer. Fire Technol 51(6):1285-1309

16. Di Blasi C, Hernandez EG, Santoro A (2000) Radiative pyrolysis of single moist wood particles. Ind Eng Chem Res 39(4):873-882

17. Association TD (1953) Timber and fire protection. The Timber Development Association Ltd., London

18. Bamford C (n.d.) The combustion of wood (unpublished)

19. Schaffer E (1973) Effect of pyrolytic temperatures on longitudinal strength of dry Douglas-fir. J Test Eval 1(4):319-329

20. White RH, Dietenberger MA (2001) Wood products: thermal degradation and fire. In: Encyclopedia of materials, science and technology, Elsevier Science Ltd., pp 97129716

21. Shen D, Fang M, Luo Z, Cen K (2007) Modeling pyrolysis of wet wood under external heat flux. Fire Saf J 42(3):210-217

22. Lautenberger C, Sexton S, Rich D (2014) Understanding long term low temperature ignition of wood. Paper presented at the international symposium on fire investigation science and technology, College Park, MD, September 22-24

23. Li W, Sun N, Stoner B, Jiang X, Lu X, Rogers RD (2011) Rapid dissolution of lignocellulosic biomass in ionic liquids using temperatures above the glass transition of lignin. Green Chem 13(8):2038-2047

24. Sakata I, Senju R (1975) Thermoplastic behavior of lignin with various synthetic plasticizers. J Appl Polym Sci 19(10):2799-2810

25. Salmén L (1984) Viscoelastic properties of in situ lignin under water-saturated conditions. J Mater Sci 19(9):3090-3096

26. Moraes P, Rogaume Y, Bocquet J, Triboulot P (2005) Influence of temperature on the embedding strength. Holz als Roh-und Werkstoff 63(4):297-302 
27. Hugi E, Wuersch M, Risi W, Wakili KG (2007) Correlation between charring rate and oxygen permeability for 12 different wood species. J Wood Sci 53(1):71-75

28. Schaffer EL, Marx CM, Bender DA, Woeste FE (1986) Strength validation and fire endurance of glued-laminated timber beams. Dept of Agriculture, Forest Service, Forest Products Laboratory, Madison

29. Yang H, Yan R, Chen H, Lee DH, Zheng C (2007) Characteristics of hemicellulose, cellulose and lignin pyrolysis. Fuel 86(12):1781-1788

30. Bojkovic Z, Kacprzyk J, Mastorakis N, Mladenov V, Revetria R (eds) (2011) EE'11 Proceedings of the 6th IASME/WSEAS international conference on energy \& environment, World Scientific and Engineering Academy and Society (WSEAS) Stevens Point, Wisconsin, 23 Feb 2011, pp 137-142

31. Shen D, Gu S (2009) The mechanism for thermal decomposition of cellulose and its main products. Biores Technol 100(24):6496-6504

32. Kashiwagi T, Ohlemiller T, Werner K (1987) Effects of external radiant flux and ambient oxygen concentration on nonflaming gasification rates and evolved products of white pine. Combust Flame 69(3):331-345

33. Ohlemiller T, Kashiwagi T, Werner K (1987) Wood gasification at fire level heat fluxes. Combust Flame 69(2):155-170

34. Kawamoto H, Morisaki H, Saka S (2009) Secondary decomposition of levoglucosan in pyrolytic production from cellulosic biomass. J Anal Appl Pyrol 85(1):247-251

35. Wichman IS, Atreya A (1987) A simplified model for the pyrolysis of charring materials. Combust Flame 68(3):231-247

36. Torero JL (2008) Flaming ignition of solid fuels. In: Dinenno PJ, Drysdale D, Beyler CL, Walton WD, Custer RLp (eds) SFPE handbook of fire protection engineering, Published by the National Fire Protection Association, National Fire Protection Association, Inc., One Batterymarch Park Quincy, Massachusetts

37. Hottel HC (1942) Report on "wood flammability under various conditions of irradiation". National Defense Research Committee of the Office of Scientific Research and Development

38. Simms D (1963) On the pilot ignition of wood by radiation. Combust Flame 7:253261

39. Moghtaderi B, Novozhilov V, Fletcher D, Kent J (1997) A new correlation for benchscale piloted ignition data of wood. Fire Saf J 29(1):41-59

40. Shields T, Silcock G, Murray J (1993) The effects of geometry and ignition mode on ignition times obtained using a cone calorimeter and ISO ignitability apparatus. Fire Mater 17(1):25-32

41. McAllister S, Finney M, Cohen J (2011) Critical mass flux for flaming ignition of wood as a function of external radiant heat flux and moisture content. In: 7th US national technical meeting of the Combustion Institute, Georgia Institute of Technology, Atlanta, GA, pp 20-23

42. McAllister S (2013) Critical mass flux for flaming ignition of wet wood. Fire Saf J 61:200-206. https://doi.org/10.1016/j.firesaf.2013.09.002

43. Janssens M (1991) Piloted ignition of wood: a review. Fire Mater 15(4):151-167

44. Angell H, Gottschalk F, McFarland W (1949) Ignition temperature of fireproofed wood, untreated sound wood and untreated decayed wood. Br Columbia Lumberm 33(57-58):70-72

45. Markwardt LJ, Bruce HD, Freas AD (1954) Brief descriptions of some fire-test methods used for wood and wood-base materials. Paper presented at the third conference on wood technology, Paris, France, 17-26 May 1954 
46. Ashton LA (1970) Fire and timber in modern building design. TRADA Publication. The Timber Research and Development Association Ltd., High Wycombe

47. Crielaard R (2015) Self-extinguishment of cross-laminated timber. MSc, Delft University of Technology

48. Ohlemiller T (2002) Smoldering combustion. In: DiNenno PJ, Drysdale D, Beyler CL et al. (eds) SFPE Handbook of Fire Protection Engineering. National Fire Protection Association, Quincy, MA, pp 2-200-202-210

49. Atreya A, Wichman I (1989) Heat and mass transfer during piloted ignition of cellulosic solids. J Heat Transf 111(3):719-725

50. Atreya A, Carpentier C, Harkleroad M (1986) Effect of sample orientation on piloted ignition and flame spread. Fire Saf Sci 1:97-109

51. Bixel EC, Moore HJ (1910) Are fires caused by steam pipes. Case School of Applied Science, Pittsburgh

52. Brown CR (1935) The determination of the ignition temperatures of solid materials. Fuel 14(2):14-18, 56-59, 80-85, 112-116, 144-152, 173-179

53. Brown CR (1934) The ignition temperatures of solid materials. Q Natl Fire Prot Assoc 28(2):135-145

54. Fangrat J, Hasemi Y, Yoshida M, Hirata T (1996) Surface temperature at ignition of wooden based slabs. Fire Saf J 27(3):249-259

55. Fons WL (1950) Heating and ignition of small wood cylinders. Ind Eng Chem 42(10):2130-2133

56. Graf S (1949) Ignition temperatures of various papers. Woods, and fabrics (Oregon State College Bull 26), Oregon State College, Corvallis (March 1949)

57. Hill HB, Comey AM (1886) On the behavior of sound and decayed wood at high temperatures. In: Proceedings of the American Academy of Arts and Sciences, JSTOR, pp $482-487$

58. Lawson DI, Simms DL (1952) The ignition of wood by radiation. Br J Appl Phys 3(9): 288

59. Simms D (1960) Ignition of cellulosic materials by radiation. Combust Flame 4:293300

60. Simms D, Hird D (1958) On the pilot ignition of materials by radiation. Department of Scientific and Industrial Research and Fire Offices' Committee, Joint Fire Research Organization FR Note (365)

61. Simms D, Law M (1967) The ignition of wet and dry wood by radiation. Combust Flame 11(5):377-388

62. Smith W, King JB (1970) Surface temperature of materials during radiant heating to ignition. J Fire Flammabl 1(4):272-288

63. Spearpoint M, Quintiere J (2000) Predicting the burning of wood using an integral model. Combust Flame 123(3):308-325

64. Tran HC, White RH (1992) Burning rate of solid wood measured in a heat release rate calorimeter. Fire Mater 16(4):197-206

65. Mikkola E (1992) Ignitability of solid materials. In: Babrauskas V, Grayson SJ (eds) Heat release in fires. Elsevier Applied Science, Barking, pp 225-232

66. Dai J, Delichatsios MA, Yang L, Zhang J (2013) Piloted ignition and extinction for solid fuels. Proc Combust Inst 34(2):2487-2495. https://doi.org/10.1016/ j.proci.2012.07.021

67. Lau PW, White R, Van Zeeland I (1999) Modelling the charring behaviour of structural lumber. Fire Mater 23(5):209-216

68. Rasbash D, Drysdale D, Deepak D (1986) Critical heat and mass transfer at pilot ignition and extinction of a material. Fire Saf J 10(1):1-10 
69. White RH, Nordheim EV (1992) Charring rate of wood for ASTM E 119 exposure. Fire Technol 28(1):5-30

70. Ritchie SJ, Steckler KD, Hamins A, Cleary TG, Yang JC, Kashiwagi T (1997) The effect of sample size on the heat release rate of charring materials. In: Fire safety science: proceedings of the fifth international symposium, pp 177-188

71. Butler C (1971) Notes on charring rates in wood. Department of the Environment and Fire Offices' Committee, Joint Fire Research Organization

72. Delichatsios MA (2005) Piloted ignition times, critical heat fluxes and mass loss rates at reduced oxygen atmospheres. Fire Saf J 40(3):197-212

73. Quintiere JG, Rangwala AS (2004) A theory for flame extinction based on flame temperature. Fire Mater 28(5):387-402. https://doi.org/10.1002/fam.835

74. Tewarson A, Pion RF (1976) Flammability of plastics-I. Burning intensity. Combust Flame 26:85-103. https://doi.org/10.1016/0010-2180(76)90059-6

75. Bamford C, Crank J, Malan D (1946) The combustion of wood. Part I. In: Mathematical proceedings of the Cambridge Philosophical Society, vol 02. Cambridge Univ Press, Cambridge, pp 166-182. https://doi.org/10.1017/S030500410002288X

76. Hottel HC (1931) Radiant heat transmission between surfaces separated by non-absorbing media. J Heat Trans 53:265-273

77. Hamilton DC, Morgan WR (1952) Radiant-interchange configuration factors. NASA, Washington

78. Bartlett A, Hadden R, Bisby L, Law A (2015) Analysis of cross-laminated timber charring rates upon exposure to non-standard heating conditions. Paper presented at the fire and materials, San Francisco, CA, 2-4 February

79. Cachim PB, Franssen J-M (2010) Assessment of Eurocode 5 charring rate calculation methods. Fire Technol 46(1):169-181

80. Timber Research and Development Association. Research Report WT/RR/10, High Wycombe

81. Wood and Fire Safety (1996) Proceedings on 3rd international scientific conference, The High Tatras, Slovak Republic. [Zvolen, Slovak Republic]: Technical University of Zvolen, Faculty of Wood Technology, pp 175-183

82. Schaffer EL (1967) Charring rate of selected woods - transverse to grain. DTIC Document

83. White RH (2000) Charring rate of composite timber products. In: Proceedings of the 3rd Wood and Fire Safety Conference, Technical University of Zvolen, Zvolen, Slovak Republic, p 353

84. Collier PCR (1992) Charring rates of timber. Building Research Association of New Zealand, Judgeford

85. Lizhong Y, Yupeng Z, Yafei W, Zaifu G (2008) Predicting charring rate of woods exposed to time-increasing and constant heat fluxes. J Anal Appl Pyrol 81(1):1-6

86. White RH (2002) Analytical methods for determining fire resistance of timber members. In: Dinenno PJ, Drysdale D, Beyler CL, Walton WD, Custer RLP, Hall JR, Watts JM (eds) The SFPE handbook of fire protection engineering, 3rd edn. National Fire Protection Association, Quincy

87. Yang T-H, Wang S-Y, Tsai M-J, Lin C-Y (2009) Temperature distribution within glued laminated timber during a standard fire exposure test. Mater Des 30(3):518-525

88. Yang T-H, Wang S-Y, Tsai M-J, Lin C-Y (2009) The charring depth and charring rate of glued laminated timber after a standard fire exposure test. Build Environ 44(2):231-236

89. Njankouo JM, Dotreppe JC, Franssen JM (2004) Experimental study of the charring rate of tropical hardwoods. Fire Mater 28(1):15-24 
90. Cachim PB, Franssen JM (2009) Comparison between the charring rate model and the conductive model of Eurocode 5. Fire Mater 33(3):129-143

91. Lie T (1994) Structural fire protection, manuals and reports on engineering practice, No. 78. ASCE, New York

92. ISO (1999) ISO 834-1: fire resistance tests. Elements of building construction. Part 1: general requirements. International Organisation for Standardization, Geneva

93. Frangi A, Fontana M (2003) Charring rates and temperature profiles of wood sections. Fire Mater 27(2):91-102

94. Cedering M (2006) Effect on the charring rate of wood in fire due to oxygen content, moisture content and wood density. In: Proceedings of the fourth international conference structures in fire ( $\left.\mathrm{SiF}^{\prime} 06\right)$

95. ASTM (2014) ASTM E 119 standard test methods for fire tests of building construction and materials. ASTM International, West Conshohocken

96. Bartlett AI, Lange D, Anderson J, Hadden RM (2017) Uncertainty quantification applied to a fire-exposed glued-laminated timber beam. In: Caspeele R, Taerwe L, Proske D (eds) 14th international probabilistic workshop. Springer, Cham, pp 203213. https://doi.org/10.1007/978-3-319-47886-9_14

97. Babrauskas V (2005) Charring rate of wood as a tool for fire investigations. Fire Saf $\mathbf{J}$ 40(6):528-554

98. Reszka P, Torero J (2008) In-depth temperature measurements in wood exposed to intense radiant energy. Exp Thermal Fluid Sci 32(7):1405-1411

99. SAA (2005) AS 1530: methods for fire tests on building materials, components and structures. Part 4: fire-resistance test of elements of construction. Standards Australia Limited, Homebush

100. Simpson WT (1998) Equilibrium moisture content of wood in outdoor locations in the United States and worldwide, vol 268. US Dept. of Agriculture, Forest Service, Forest Products Laboratory

101. ASTM (2003) ASTM D 4442-92 standard test methods for direct moisture content measurement of wood and wood-base materials. ASTM International, West Conshohocken

102. Moore J (2011) Wood properties and uses of Sitka spruce in Britain. Forestry Commission Research Report. Forestry Commission

103. Di Blasi C, Branca C, Santoro A, Gonzalez Hernandez E (2001) Pyrolytic behavior and products of some wood varieties. Combust Flame 124(1):165-177

104. Lizhong Y, Zaifu G, Yupeng Z, Weicheng F (2007) The influence of different external heating ways on pyrolysis and spontaneous ignition of some woods. J Anal Appl Pyrol 78(1):40-45

105. Nurbakhsh S (1989) Thermal decomposition of charring materials. Michigan State Univ., East Lansing

106. Bryan J, Doman L (1940) Fire resistance. The comparative resistance to fire of various species of timber. Wood 5:19-23

107. Barnes A (1940) Fallacies about fire resistance. Wood 5:267-269

108. Ashton LA, Webster CT (1951) Investigation on building fires, Part IV, fire resistance of timber doors. National Building Studies, London

109. Várhegyi G, Grønli MG, Di Blasi C (2004) Effects of sample origin, extraction, and hot-water washing on the devolatilization kinetics of chestnut wood. Ind Eng Chem Res 43(10):2356-2367

110. Hadden R, Alkatib A, Rein G, Torero J (2014) Radiant ignition of polyurethane foam: the effect of sample size. Fire Technol 50(3):673-691. https://doi.org/10.1007/ s10694-012-0257-x 
111. Suuberg EM, Milosavljevic I, Lilly W (1994) Behavior of charring materials in simulated fire environments. US Department of Commerce, National Institute of Standards and Technology, Gaithersburg

112. Majamaa J (1991) Calculation models of wooden beams exposed to fire. Technical Research Centre of Finland

113. Murty Kanury A, Blackshear PL Jr (1970) Some considerations pertaining to the problem of wood-burning. Combust Sci Technol 1(5):339-356

114. Buchanan AH, Barber D (1994) Fire resistance of epoxied steel rods in glulam timber. In: Proceedings of Pacific timber engineering conference, Gold Coast, Australia

115. Schmid J, König J, Köhler J (2010) Design model for fire exposed cross-laminated timber. In: Proceedings of the sixth international conference structures in fire, Lancaster, US

116. Frangi A, Fontana M, Hugi E, Jöbstl R (2009) Experimental analysis of cross-laminated timber panels in fire. Fire Saf J 44(8):1078-1087

117. Hakkarainen $T$ (2002) Post-flashover fires in light and heavy timber construction compartments. J Fire Sci 20(2):133-175

118. Hasburgh L, Bourne K, Dagenais C, Ranger L, Roy-Poirier A (2016) Fire performance of mass-timber encapsulation methods and the effect of encapsulation on char rate of cross-laminated timber. Paper presented at the world conference on timber engineering, Vienna, Austria, 22-25 August

119. Frangi A, Fontana M, Knobloch M, Bochicchio G (2008) Fire behaviour of crosslaminated solid timber panels. Fire Saf Sci 9:1279-1290

120. Schmid J, Klippel M, Just A, Frangi A (2014) Review and analysis of fire resistance tests of timber members in bending, tension and compression with respect to the reduced cross-section method. Fire Saf J 68:81-99

121. Friquin KL, Grimsbu M, Hovde PJ (2010) Charring rates for cross-laminated timber panels exposed to standard and parametric fires. In: World conference on timber engineering, pp 20-24

122. Wakefield T, He Y, Dowling V (2009) An experimental study of solid timber external wall performance under simulated bushfire attack. Build Environ 44(10):2150-2157

123. Milosavljevic I, Oja V, Suuberg EM (1996) Thermal effects in cellulose pyrolysis: relationship to char formation processes. Ind Eng Chem Res 35(3):653-662

124. Schaffer EL (1964) An approach to the mathematical prediction of temperature rise within a semi-infinite wood slab subjected to high-temperature conditions. Forest Products Laboratory

125. Ashton LA (1965) Behaviour in fire of wood-based panel products. In: Plywood and other 1683 wood-based panels (Vol IV), Food and Agriculture Organization of the United Nations, Paper 5, 15

126. Hadden RM, Bartlett AI, Hidalgo JP, Santamaria S, Wiesner F, Bisby LA, Deeny S, Lane B (2017) Effects of exposed cross laminated timber on compartment fire dynamics. Fire Saf J 91:480-489. https://doi.org/10.1016/j.firesaf.2017.03.074

127. König $\mathbf{J}$ (2006) Effective thermal actions and thermal properties of timber members in natural fires. Fire Mater 30(1):51-63

128. Silcock G, Shields T (2001) Relating char depth to fire severity conditions. Fire Mater 25(1):9-11

129. Reszka P (2008) In-depth temperature profiles in pyrolyzing wood, $\mathrm{PhD}$ Thesis, the University of Edinburgh, June 2008

130. Hill HB, Comey AM (1886) On the decomposition of wood at high temperatures. In: Proceedings of the American Academy of Arts and Sciences, JSTOR, pp 488-492 
131. Jowsey A (2006) Fire imposed heat fluxes for structural analysis. PhD Thesis, The University of Edinburgh

Publisher's Note Springer Nature remains neutral with regard to jurisdictional claims in published maps and institutional affiliations. 